\title{
Endocrine and behavioural responses to acute central CRF challenge are antagonized in the periphery and CNS, respectively, in C57BL/6 mice
}

\author{
Pryce, C R ; Siegl, S ; Mayer, R ; Rahmanzadeh, G ; McAllister, K H
}

\begin{abstract}
Corticotropin releasing factor $(\mathrm{CRF})$ is a major mediator of central and peripheral responses to environmental stressors, and antagonism of its receptors (CRF-R1, -R2) is an active area of pharmacotherapeutic research for stress-related disorders. Stress responses include CRF activation of the hypothalamus-pituitary-adrenal axis and behavioural inhibition. Valid in vivo models for the study of these neuro-endocrine and -behavioural CRF pathways and their central-peripheral antagonism are important. The aims of this study in C57BL/6 mice were to describe the acute effects of intracerebroventricular (ICV) CRF using plasma ACTH-CORT titres and locomotor activity as readouts, and to study the impact on these readouts of central versus peripheral pre-treatment with the CRF-R $1 / 2$ antagonist, astressin. The following experiments were performed: Effects of (i) serial blood sampling (SBS) per se, (ii) physical confinement+SBS, (iii) ICV saline infusion+SBS, on plasma titres of ACTH-CORT. (iv) Effects of ICV or IP CRF infusion on plasma ACTH-CORT. (v) Effects of ICV CRF on plasma CRF. (vi) Effects of ICV or IP astressin on ICV or IP CRF-stimulated plasma CORT. (vii) Effects of ICV or IP astressin on ICV CRF-induced locomotor inactivity. Main findings were: (i)-(ii) Serial blood sampling per se and physical confinement+SBS led to similar, mild increases in plasma ACTH-CORT. (iii) ICV saline infusion led to a marked increase in plasma ACTH, possibly due to assay crossreactivity with "washed out" pituitary peptides, and a mild increase in plasma CORT. (iv) ICV CRF (0.001-1 g) induced no further increase in plasma ACTH versus vehicle, and induced dose-dependent increased plasma CORT. $1 \mathrm{~g}$ ICV CRF also reduced locomotor activity. (v) ICV CRF-induced dose-dependent increased plasma CRF. (vi) ICV astressin failed to block ICV CRF-induced increased plasma CORT, whereas IP astressin did do so. (vii) ICV CRF-induced locomotor inactivity was blocked by ICV astressin, but not by IP astressin. Therefore, ICV CRF-induced a dose-dependent increase in plasma CORT via a peripheral pathway and a reduction in locomotion via a central pathway, indicated by the double dissociation in the ability of astressin to antagonize these effects relative to its route of administration, IP or ICV, respectively. The preparation described here could be readily used to provide initial indications on the central and peripheral activity of CRF-R antagonists, including pharmacokinetics following peripheral administration.
\end{abstract}

DOI: https://doi.org/10.1016/j.neuropharm.2010.09.015

Posted at the Zurich Open Repository and Archive, University of Zurich

ZORA URL: https://doi.org/10.5167/uzh-45227

Journal Article

Accepted Version

Originally published at: 
Pryce, C R; Siegl, S; Mayer, R; Rahmanzadeh, G; McAllister, K H (2011). Endocrine and behavioural responses to acute central $\mathrm{CRF}$ challenge are antagonized in the periphery and CNS, respectively, in C57BL/6 mice. Neuropharmacology, 60(2-3):318-327.

DOI: https://doi.org/10.1016/j.neuropharm.2010.09.015 


\section{Elsevier Editorial System(tm) for Neuropharmacology}

Manuscript Draft

Manuscript Number: NEUROPHARM-D-10-00296R1

Title: Endocrine and behavioural responses to acute central CRF challenge are antagonised in the periphery and CNS, respectively, in C57BL/6 mice

Article Type: Research Paper

Section/Category: Systems and Disease

Keywords: Mouse; CRF; HPA; Activity; Astressin

Corresponding Author: Dr. Christopher Pryce, Ph.D.

Corresponding Author's Institution: University of Zurich

First Author: Christopher Pryce, Ph.D.

Order of Authors: Christopher Pryce, Ph.D.; Stephanie Siegl, BSc; Roland Mayer; Gholamreza

Rahmanzadeh, BSc; Kevin H McAllister, PhD

Abstract: Corticotropin releasing factor (CRF) is a major mediator of central and peripheral responses to environmental stressors, and antagonism of its receptors (CRF-R1, -R2) is an active area of pharmacotherapeutic research for stress-related disorders. Stress responses include CRF activation of the hypothalamus-pituitary-adrenal axis and behavioural inhibition. Valid in vivo models for the study of these neuro-endocrine and -behavioural CRF pathways and their central-peripheral antagonism are important. The aims of this study in C57BL/6 mice were to describe the acute effects of intracerebroventricular (ICV) CRF using plasma ACTH-CORT titres and locomotor activity as readouts, and to study the impact on these readouts of central versus peripheral pretreatment with the CRFR1/2 antagonist, astressin. The following experiments were performed: Effects of (i) serial blood sampling (SBS) per se, (ii) physical confinement + SBS, (iii) ICV saline infusion + SBS, on plasma titres of ACTH-CORT. (iv) Effects of ICV or IP CRF infusion on plasma ACTH-CORT. (v) Effects of ICV CRF on plasma CRF. (vi) Effects of ICV or IP astressin on ICV or IP CRF-stimulated plasma CORT. (vii) Effects of ICV or IP astressin on ICV CRF-induced locomotor inactivity. Main findings were: (i)-(ii) Serial blood sampling per se and physical confinement + SBS led to similar, mild increases in plasma ACTH-CORT. (iii) ICV saline infusion led to a marked increase in plasma ACTH, possibly due to assay crossreactivity with "washed out" pituitary peptides, and a mild increase in plasma CORT. (iv) ICV CRF (0.001-1 $\mu \mathrm{g}$ ) induced no further increase in plasma ACTH versus vehicle, and induced dose-dependent increased plasma CORT. $1 \mu \mathrm{g}$ ICV CRF also reduced locomotor activity. (v) ICV CRF induced dose-dependent increased plasma CRF. (vi) ICV astressin failed to block ICV CRF-induced increased plasma CORT, whereas IP astressin did do so. (vii) ICV CRF-induced locomotor inactivity was blocked by ICV astressin, but not by IP astressin. Therefore, ICV CRF induced a dose-dependent increase in plasma CORT via a peripheral pathway and a reduction in locomotion via a central pathway, indicated by the double dissociation in the ability of astressin to antagonize these effects relative to its route of administration, IP or ICV, respectively. The preparation described here could be readily used to provide initial indications on the central and peripheral activity of CRF-R antagonists, including pharmacokinetics following peripheral administration. 

Dear Ms. Yeates, Dear Prof. Markou,

Thank you very much to you and the reviewers for the very constructive and helpful criticism of the manuscript. All of the comments have been taken into account and the manuscript has been revised accordingly. The details of the revisions undertaken are stated point-by-point below. The changes made in the revised manuscript relative to the original are highlighted in bold font in the revision.

My co-authors and I look forward to your reply on the suitability of the revised manuscript for publication in Neuropharmacology in due course.

Thank you and yours sincerely,

Christopher Pryce 


\section{Responses to Reviewers}

\section{Editor's comments:}

Both reviewers found your work mostly well conducted and of potential interest to the field. There are, however, some issues that the reviewers raised that need to be addressed with specific changes in the manuscript. For example, the limitation of drawing conclusions from a single dose study (absence of dose-response function) needs to be discussed in the Discussion. In addition, both Reviewers questioned the clarity of Figure 7. Finally, I would like to ask you that all $p$ values are reported as "less than" (rather than equal) unless there is reference to a very strong statistical trend.

Responses: The limitation of drawing conclusions from a single dose study is now discussed. Figure 7A upper graph has been deleted. All significant $p$ values are now reported as less than $(<)$.

Reviewer \#1: Accumulating evidence supports a role for CRF receptor antagonists among the future pharmacotherapies for the treatment of stress-related disorders. However, one major difficulty is to address the efficacy of CRHR antagonists in convenient animal experiments. In this manuscript Pryce and colleagues systematically analyze the acute effects of CRF application using plasma ACTH and corticosterone levels as well as locomotor activity as functional readouts. Subsequently the authors investigate the impact of the well established CRF receptor antagonist astressin on these CRF-evoked measures. Moreover, the authors are able to discriminate between central and peripheral effects of $\mathrm{CRH}$ and astressin, respectively. Taken together, the manuscript convincingly demonstrates the usefulness of plasma ACTH and corticosterone as well as locomotor activity to assess the central and peripheral effects of a given CRF receptor antagonist. This is a very systematic and solid work properly addressing an important issue in the field. Hence, criticisms or suggestions are only minor:

1. Introduction, page 5, bottom: The authors state that constitutive CRF over-expressing mice show hypo-activity in a novel cage and increased activity on an elevated plus maze. However, in the publication from Stenzel-Poore and colleagues (1994) no increased activity but increased anxiety was observed on the EPM. This should be corrected.

Response: This statement has been corrected in the revised Introduction ( page 5).

2. The intention of Figure 7A does not get very clear from the legend. It seems that the upper graph depicts the mean of all animals subsequently shown in the bottom graph. It would be more informative to show the locomotor behavior for each treatment group individually.

Response: The upper graph of Figure 7A has been deleted from the revision. The purpose of this graph was to depict the significant main effect of the repeated measure of time on locomotor activity, given that there was no Group x Time interaction. The significant main effect of time is now described more fully in the text (page 18).

Minor:

Figure legend of Figure 1: tail-vein instead of tain-vein

Response: Text corrected. 
Reviewer \#2: This is a very thorough and nice set of studies comparing peripheral vs. central mechanisms for ICV CRF effects on CORT release in mice. Essentially it appears that peripheral but not central administration of CRF antagonists blocks CRF-induced increases in CORT. A nice element to the study is that the same central dose of the antagonist does block CRF-induced decreases in locomotor activity, providing a good positive control for the single astressin dose used. I think this is a very useful paper for the field.

Usually there is a concern about only using one dose when there is a negative finding (e.g. ICV astressin effects on CORT), however the double dissociation between IP and ICV astressin effects on CORT vs locomotor activity was sufficiently convincing to leave this usual concern relatively minor.

Response: This limitation of the study, together with the explanation of why it does not compromise the study, is now stated explicitly at the end of the revised Discussion (page 25).

Some suggestions and comments:

Figure $7 \mathrm{a}$ is an odd graph, why are the treatment groups averaged together, this does not seem informative in any way. IF there is no treatment $X$ time effect, then it is reasonable to only show the data collapsed across the entire time block.

Response: Only the Group-specific means across the entire time block are now shown in Figure $7 \mathrm{~A}$ and the main effect of Time is now described in the text only.

Why is there no ip AST/icv Vehicle group in the CORT release studies? It seems of interest to find if and by what route astressin can reduce endogenous CRF/urocortin effects on CORT/ACTH, since there the first experiments demonstrate an increase in baseline CORT after the stress or simply ICV infusions. (e.g. are stress-induced increases in CORT also blocked by peripheral astressin, or does it just block the effects of exogenous CRF treatment?).

Response: This point is now discussed explicitly in the revised Discussion (page 23).

It would be helpful to have axis range the same for graphs using the same measure (e.g. CORT, Figure 5).

Response: The figures have been checked and corrected (Figure 5) so that adjacent graphs using the same measure have the same axis range.

The methods and discussion conflict about what the vehicle is for astressin, the methods indicate it is double distilled water, but in the discussion it is referred to as being saline.

Response: The Discussion has been corrected and now states that water was the vehicle for astressin (page 21). 
Endocrine and behavioural responses to acute central CRF challenge are antagonised in the periphery and CNS, respectively, in C57BL/6 mice

Christopher R. Pryce ${ }^{a b^{*}}$, Stephanie Siegl ${ }^{\mathrm{a} 1}$, Roland Mayer ${ }^{\mathrm{a}}$, Gholamreza Rahmanzadeh ${ }^{\mathrm{a}}$ and Kevin H. McAllister ${ }^{\mathrm{a}}$

a Neuroscience Disease Area, Novartis Institutes for Biomedical Research, Novartis Pharma, Basel $\mathrm{CH}-4002$, Switzerland

b Clinic for Affective Disorders \& General Psychiatry, Psychiatric University Hospital Zurich, Zurich, Switzerland

1 Present address: Institut für Pharmakologie \& Toxikologie, Universitätsklinikum, Aachen, Germany

${ }^{*}$ Corresponding author:

Preclinical Laboratory for Translational Research into Affective Disorders, Clinic for Affective Disorders \& General Psychiatry, Psychiatric University Hospital Zurich, August Forel-Strasse 1, $\mathrm{CH}-8008$ Zurich, Switzerland. Tel.: +41 44634 8921; fax.: +41 446348951 . E-mail: $\underline{\text { Christopher.pryce@bli.uzh.ch }}$

E-mail addresses

ssiegl@ukaachen.de

roland.mayer@novartis.com

gholamreza.rahmanzadeh@novartis.com

kevin.mcallister@novartis.com 


\section{ABSTRACT}

Corticotropin releasing factor (CRF) is a major mediator of central and peripheral responses to environmental stressors, and antagonism of its receptors (CRF-R1, -R2) is an active area of pharmacotherapeutic research for stress-related disorders. Stress responses include CRF activation of the hypothalamus-pituitary-adrenal axis and behavioural inhibition. Valid in vivo models for the study of these neuro-endocrine and -behavioural CRF pathways and their centralperipheral antagonism are important. The aims of this study in C57BL/6 mice were to describe the acute effects of intracerebroventricular (ICV) CRF using plasma ACTH-CORT titres and locomotor activity as readouts, and to study the impact on these readouts of central versus peripheral pretreatment with the CRF-R1/2 antagonist, astressin. The following experiments were performed: Effects of (i) serial blood sampling (SBS) per se, (ii) physical confinement + SBS, (iii) ICV saline infusion + SBS, on plasma titres of ACTH-CORT. (iv) Effects of ICV or IP CRF infusion on plasma ACTH-CORT. (v) Effects of ICV CRF on plasma CRF. (vi) Effects of ICV or IP astressin on ICV or IP CRF-stimulated plasma CORT. (vii) Effects of ICV or IP astressin on ICV CRF-induced locomotor inactivity. Main findings were: (i)-(ii) Serial blood sampling per se and physical confinement + SBS led to similar, mild increases in plasma ACTH-CORT. (iii) ICV saline infusion led to a marked increase in plasma $\mathrm{ACTH}$, possibly due to assay crossreactivity with "washed out" pituitary peptides, and a mild increase in plasma CORT. (iv) ICV CRF $(0.001-1 \mu \mathrm{g})$ induced no further increase in plasma ACTH versus vehicle, and induced dose-dependent increased plasma CORT. $1 \mu \mathrm{g}$ ICV CRF also reduced locomotor activity. (v) ICV CRF induced dose-dependent increased plasma CRF. (vi) ICV astressin failed to block ICV CRF-induced increased plasma CORT, whereas IP astressin did do so. (vii) ICV CRF-induced locomotor inactivity was blocked by ICV astressin, but not by IP astressin. Therefore, ICV CRF induced a dose-dependent increase in plasma CORT via a peripheral pathway and a reduction in locomotion via a central pathway, indicated by the double dissociation in the ability of astressin to 
antagonize these effects relative to its route of administration, IP or ICV, respectively. The preparation described here could be readily used to provide initial indications on the central and peripheral activity of CRF-R antagonists, including pharmacokinetics following peripheral administration.

Keywords: Mouse; CRF; HPA; Activity; Astressin 


\section{Endocrine and behavioural responses to acute central CRF challenge are antagonised in the periphery and CNS, respectively, in C57BL/6 mice}

Christopher R. Pryce ${ }^{a b^{*}}$, Stephanie Siegl ${ }^{a 1}$, Roland Mayer ${ }^{a}$, Gholamreza Rahmanzadeh ${ }^{a}$ and Kevin H. McAllister ${ }^{\mathrm{a}}$

a Neuroscience Disease Area, Novartis Institutes for Biomedical Research, Novartis Pharma, Basel CH-4002, Switzerland

b Clinic for Affective Disorders \& General Psychiatry, Psychiatric University Hospital Zurich, Zurich, Switzerland

1 Present address: Institut für Pharmakologie \& Toxikologie, Universitätsklinikum, Aachen, Germany

* Corresponding author:

Preclinical Laboratory for Translational Research into Affective Disorders, Clinic for Affective Disorders \& General Psychiatry, Psychiatric University Hospital Zurich, August Forel-Strasse 1, CH-8008 Zurich, Switzerland. Tel.: +41 $44 \quad 634$ 8921; fax.: +41 446348951 . E-mail: Christopher.pryce@bli.uzh.ch

E-mail addresses

ssiegl@ukaachen.de

roland.mayer@novartis.com

gholamreza.rahmanzadeh@novartis.com

kevin.mcallister@novartis.com 


\section{ABSTRACT}

Corticotropin releasing factor (CRF) is a major mediator of central and peripheral responses to environmental stressors, and antagonism of its receptors (CRF-R1, -R2) is an active area of pharmacotherapeutic research for stress-related disorders. Stress responses include CRF activation of the hypothalamus-pituitary-adrenal axis and behavioural inhibition. Valid in vivo models for the study of these neuro-endocrine and -behavioural CRF pathways and their centralperipheral antagonism are important. The aims of this study in C57BL/6 mice were to describe the acute effects of intracerebroventricular (ICV) CRF using plasma ACTH-CORT titres and locomotor activity as readouts, and to study the impact on these readouts of central versus peripheral pretreatment with the CRF-R1/2 antagonist, astressin. The following experiments were performed: Effects of (i) serial blood sampling (SBS) per se, (ii) physical confinement + SBS, (iii) ICV saline infusion + SBS, on plasma titres of ACTH-CORT. (iv) Effects of ICV or IP CRF infusion on plasma ACTH-CORT. (v) Effects of ICV CRF on plasma CRF. (vi) Effects of ICV or IP astressin on ICV or IP CRF-stimulated plasma CORT. (vii) Effects of ICV or IP astressin on ICV CRF-induced locomotor inactivity. Main findings were: (i)-(ii) Serial blood sampling per se and physical confinement + SBS led to similar, mild increases in plasma ACTH-CORT. (iii) ICV saline infusion led to a marked increase in plasma $\mathrm{ACTH}$, possibly due to assay crossreactivity with "washed out" pituitary peptides, and a mild increase in plasma CORT. (iv) ICV CRF $(0.001-1 \mu \mathrm{g})$ induced no further increase in plasma ACTH versus vehicle, and induced dose-dependent increased plasma CORT. $1 \mu \mathrm{g}$ ICV CRF also reduced locomotor activity. (v) ICV CRF induced dose-dependent increased plasma CRF. (vi) ICV astressin failed to block ICV CRF-induced increased plasma CORT, whereas IP astressin did do so. (vii) ICV CRF-induced locomotor inactivity was blocked by ICV astressin, but not by IP astressin. Therefore, ICV CRF induced a dose-dependent increase in plasma CORT via a peripheral pathway and a reduction in locomotion via a central pathway, indicated by the double dissociation in the ability of astressin to 
antagonize these effects relative to its route of administration, IP or ICV, respectively. The preparation described here could be readily used to provide initial indications on the central and peripheral activity of CRF-R antagonists, including pharmacokinetics following peripheral administration.

Keywords: Mouse, CRF, HPA, Activity, Astressin 


\section{Introduction}

Corticotropin releasing factor (CRF) is a neurohormone and neurotransmitter and a major mediator of physiological and behavioural responses to environmental stressors (Vale et al., 1981). An extensive immunohistochemical mapping study in rat (Swanson et al., 1983) describes: CRF-stained cells in the paraventricular nucleus of the hypothalamus (PVH) and CRF-stained fibres in the neurohaemal zone of the median eminence; a series of CRF-stained cell groups in the basal forebrain (e.g. central amygdala) and brain stem, inter-connected by CRF-stained fibres in medial forebrain bundle; and scattered CRF-stained cells throughout most areas of the cerebral cortex. An extensive in situ hybridization mapping study of mRNAs for CRF receptor type 1 (CRF-R1) and type 2 (CRF-R2) has been conducted in rat and mouse brains and pituitary glands (Van Pett et al., 2000): in both species, CRF-R1 exhibits high expression in the pituitary and a wide distribution throughout the CNS with regions of high expression including prefrontal cortex, amygdala, bed nucleus of stria terminalis (BNST), septum, basal ganglia, brain stem (e.g. periaqueductal gray, pre- and post-cerebellar regions) and cerebellum. CRF-R2 is not expressed in the pituitary, and CNS regions of high expression are more limited and include septum, BNST and brain stem dorsal raphé nucleus. The CRF synthesised by the parvocellular cells of the PVH and released into the median eminence reaches the pituitary and, in the CRF-R1-expressing corticotrope cells of the anterior pituitary, stimulates the synthesis and secretion of ACTH, which in turn stimulates corticosteroid secretion from the cortex of the adrenal gland.

In vivo study of regulation of $\mathrm{ACTH}$-corticosteroid release and behavioural processes by $\mathrm{CRF}$ is important with respect to the psychoneuroendocrinology of the stress response and development of antagonists of CRF hyperactivity as a potential treatment for stress-related disorders. Examples of important questions are does/how does forebrain CRF released as a 
neurotransmitter regulate PVH CRF neuroendocrine activity, and how do CRF-receptor antagonists regulate $\mathrm{ACTH}$-corticosteroid levels and behaviour. Some of the first major in vivo studies of CRF effects involved intra-venous (IV) or intracerebroventricular (ICV) infusion of CRF and measurement of its effects on circulating ACTH and corticosteroid levels, in rat (Rivier et al. 1982) and rhesus macaque (Rock et al., 1984). In both species there was a dose-related increase in ACTH and corticosteroid blood levels. In rats, ICV CRF has been demonstrated to induce activation, as immediate-early gene protein FOS induction, throughout the CNS with the activation pattern closely mimicking the distribution of CRF-R1 receptors (Bittencourt and Sawchenko, 2000). Behavioural studies in rat demonstrated that ICV CRF leads to, for example, increased locomotor activity in a familiar cage, decreased activity in a novel open field, and increased anxiety on an elevated plus maze (Koob et al., 1993; Sutton et al., 1982). These effects were antagonized by peptidergic CRF-R1/R2 antagonists (Spina et al., 2000). In mice, ICV CRF has been demonstrated to induce activation, as increased local cerebral glucose utilization, in hypothalamic, thalamic, cerebellar and hippocampal regions (Warnock et al., 2009). It also increased plasma corticosterone (CORT) levels (Warnock et al., 2009). Behavioural effects of ICV CRF in mice include decreased activity in a novel open field and increased time spent in the centre of the open field related to a delay in leaving the centre after being placed there at the onset of the test (Swiergiel et al., 2008). A number of transgenic mouse strains that chronically over-express CRF have been developed and phenotyped in terms of HPA and behavioural status. Constitutive-transgenic mice over-expressing CRF, including in those regions/cells expressing endogenous CRF, exhibit increased basal plasma ACTH and CORT levels (Stenzel-Poore et al., 1992), hypo-activity in a novel cage and on an elevated plus maze, and reduced percent time on the open arms, probably reflecting increased anxiety, on the elevated plus maze (Stenzel-Poore et al., 1994). Conditionaltransgenic mice in which CRF over-expression is restricted to and pertains throughout the CNS, 
exhibit no phenotype in terms of basal plasma ACTH and CORT levels and increased ACTH and CORT responses to a restraint stressor (Lu et al., 2008).

Alongside the utilisation of transgenic mice to study the effects of chronic central CRF overexpression and the neuropharmacology of CRF-R antagonism and agonism thereon, it is also important to have well-described mouse models based on acute increases in exogenous central CRF administration. These models can provide a first level of readout on the central and peripheral activity of CRF-R antagonists, including pharmacokinetic properties following peripheral administration, prior to study in transgenic models. In the present study, ICV CRF neuroendocrine challenge was conducted in C57BL/6 mice. The first aim was to describe the dose-related effects of ICV CRF on plasma ACTH and CORT levels and locomotor activity. The second and related aim was to utilize the same preparation to investigate the effects of prior treatment with a CRF-R1/R2 antagonist on ICV CRF-induced changes in plasma ACTH-CORT levels and locomotor activity. The antagonist used was astressin [cyclo(30-33) [D-Phe ${ }^{12}, \mathrm{Nle}^{21-}$ ${ }^{38}$, Glu $^{30}$, Lys ${ }^{33}$ ]-hCRF $\left.(12-41)\right]$ (Spina et al., 2000). In rat, astressin is a potent antagonist of IVCRF stimulation of ACTH when pre-administered IV and also when administered ICV at a high dose (Rivier et al., 1996; Turnbull et al., 1999). ICV Astressin also reverses the anxiogenic effect of ICV CRF on the elevated plus maze in rats (Spina et al., 2000). In the present study the effects of pre-treatment with ICV versus IP astressin on ICV CRF stimulation of ACTH and CORT blood levels were studied, as were the effects of ICV versus IP astressin on ICV CRF induced changes in locomotor activity. Firstly, the demonstration that ICV CRF stimulates changes in plasma ACTH and CORT levels and locomotor activity levels would allow for the study of astressin effects on these readouts. Secondly, any effects of astressin, given ICV or IP, would provide insights into the pathway via which ICV CRF regulates these endocrine and behavioural readouts. Thirdly, therefore, the validity of the readouts in terms of providing initial 
indications on the central or peripheral activity of putative CRF-R antagonists, could be assessed.

\section{Materials and Methods}

\subsection{Animals and maintenance}

C57BL/6N male mice (Janvier, Le Genest St. Isle, France) were maintained in pairs in Macrolon type II cages $(27 \times 21 \times 15 \mathrm{~cm}$; containing sawdust, a sleeping chamber, tissue paper and a wood stick), with water and pellet food available ad libitium. The colony room was on a reversed light-dark cycle (dark phase $0800-2000 \mathrm{~h}$ ) with temperature at $22^{\circ} \mathrm{C}$ and humidity at $50 \%$. Mice were handled for $5 \mathrm{~min}$ on each of 3 days prior to the experiment. All procedures were conducted under a permit for animal experimentation issued by the Veterinary Office, Basel, Switzerland in accordance with the Animal Protection Act (1978) Switzerland. All efforts were made to minimise the number of mice used and any suffering of those mice that were used.

\subsection{Drugs}

CRF (Sigma, St. Louis, MO, USA) was dissolved in physiological saline at the appropriate concentrations for ICV infusion or IP injection. CRF dissolved in saline and administered ICV has been demonstrated to induce activation throughout the CNS in mouse (local cerebral glucose utilization (Warnock et al., 2009)) and rat (immediate-early gene protein FOS induction (Bittencourt and Sawchenko, 2000)). Astressin (Bachem AG, Bubendorf, CH) was dissolved in double-distilled water at appropriate concentrations for ICV infusion or IP injection. Solutions were prepared immediately before use each day.

\subsection{Surgery and brain cannulation}


Mice $(n=130)$ were brain cannulated at age 10 weeks and experiments were conducted 2 weeks later. Mice were pre-treated with analgesic (Temgesic, $0.05 \mathrm{mg} / \mathrm{ml} / \mathrm{kg}$ ), anaesthetized with ketamine $(100 \mathrm{mg} / \mathrm{kg})+$ xylazine $(10 \mathrm{mg} / \mathrm{kg})$ and operated on a warming pad. The head was fixed in a stereotaxic frame and mice were prepared with 26-gauge bilateral cannulas (Plastics One) aimed above the lateral ventricles $(-0.3 \mathrm{~mm}$ posterior to bregma, $1.0 \mathrm{~mm}$ lateral from the midline, $-1.4 \mathrm{~mm}$ ventral from skull surface) (Franklin and Paxinos, 2008). Cannulas were attached to the skull using adhesive gel and secured with stainless steel screws and dental acrylic; dummy cannulas were inserted and maintained during the recovery period.

\subsection{Blood sampling}

Blood sampling involved placing the mouse in a plastic restrainer with the tail protruding through a hole in the end of the tube, making a diagonal incision on the lateral tail surface about $15 \mathrm{~mm}$ from the distal tip, and massaging $60 \mu \mathrm{l}$ of blood into an EDTA-coated capillary blood tube. Serial blood samples were collected at intervals from the same incision site. Mice were returned to the home cage in the intervals between successive blood samplings. Trunk blood sampling was conducted via decapitation and collection of the blood (300-500 $\mu \mathrm{l})$ into an EDTA-coated tube (Microvette 500, Sarstedt). All samples were placed immediately on ice and centrifuged at $4^{\circ} \mathrm{C}$ followed by removal and storage of plasma in Lo-bind cryotubes at $-80^{\circ} \mathrm{C}$ until hormone determination.

\subsection{Physical confinement stressor}

Mice were placed singly in transparent plastic tubes $(\mathrm{L}=10 \mathrm{~cm} \times \varnothing=4 \mathrm{~cm}$; Indulab, Gams, $\mathrm{CH}$ ), which were novel and in which they could move and turn, for $5 \mathrm{~min}$. Immediately following removal from the tube, mice were restrained briefly for tail vein blood sampling (time $=\min 0$ ). 
Mice were then returned to the home cage and colony room, and retrieved at min 20, 60 and 120 for serial blood sampling.

\subsection{ICV CRF infusion}

Cannulated mice were transferred in their home cage to an adjacent dimly-lit procedures room. The mouse was placed in a type II cage filled with sawdust and without lid; mice had been placed in the same cage for 5 min on each of 3 days prior to the experiment. Two 33-gauge internal cannulas extending $1.4 \mathrm{~mm}$ below the guide cannulas and connected to a double microinfusion pump were inserted. The mouse was able to move in the cage, with the delivery tube held by the experimenter, whilst CRF was infused in a total volume of $1.5 \mu \mathrm{l}$ per ventricle during $5 \mathrm{~min}$. The cannulas were removed $1 \mathrm{~min}$ after the end of infusion to allow for diffusion.

After completion of each experiment, methylene blue dye solution was infused into each cannula, using the same method and volume used for CRF delivery, the brains were removed and frozen and sections were cut on a cryostat to assess cannula placement. Those animals with dye in the lateral ventricles and third ventricle were included in the analysis.

\subsection{Astressin pre-treatment}

For the study of the effects of ICV astressin pretreatment, cannulated mice were connected with the microinfusion apparatus as described above. Astressin was infused in a total volume of $2 \mu l$ per ventricle during $5 \mathrm{~min}$. The cannulas were removed $1 \mathrm{~min}$ after the end of infusion and the

mice returned to the home cage for $15 \mathrm{~min}$, and were then infused ICV with CRF. For the study of IP effects, astressin was injected at a volume of $5 \mathrm{ml} / \mathrm{kg}$, the mice returned to the home cage for $15 \mathrm{~min}$, and were then infused ICV with CRF.

After completion of each experiment, methylene blue dye solution was infused into each cannula and histology was performed to confirm ICV cannula placement, as described above. 


\subsection{Locomotor activity in mice}

Locomotor activity was measured using an in-house apparatus comprising a type-IV cage rack that was covered at the back with aluminium and with aluminium shutters that allowed access to each cage from the front. Each isolated compartment was illuminated with a dim white house light (10 lux) and contained a type IV cage $(60 \times 38 \times 20 \mathrm{~cm})$ without lid and with fresh sawdust. A small video camera was located in the ceiling of each compartment and the image was sent to a frame grabber and analysis software. Percent second-to-second change in pixel activation was calculated and provided an arbitrary measure of two-dimensional activity per second. Total activity per 5-minute block was calculated per mouse. Mice were placed in the compartments for 2 daily 60 min habituation sessions during the $2-3$ days prior to the experiment.

\subsection{Experiments}

All experiments were performed within the daily time period of $1200-1800 \mathrm{~h}$ i.e. during the second-half of the dark/active period.

i. Effect of serial blood sampling on plasma ACTH and CORT. Naive mice $(\mathrm{n}=8)$ were blood sampled at min 0, 20, 60 and 120 .

ii. Effect of physical confinement on plasma ACTH and CORT. Naive mice $(\mathrm{n}=8)$ were exposed to 5-min confinement in a novel plastic tube followed by blood sampling at min 0,20 , 60 and 120. In 8 additional mice, removal from the home cage was followed immediately by blood sampling for measurement of basal ACTH-CORT titres.

iii. Effect of ICV saline infusion on plasma ACTH and CORT. Naive cannulated mice $(\mathrm{n}=6)$ were infused ICV with saline, followed by blood sampling at min 20, 60 and 120. In 6 additional cannulated mice, removal from the home cage was followed immediately by blood sampling for measurement of basal ACTH-CORT titres. 
iv. Effect of ICV CRF on plasma ACTH and CORT. Cannulated mice ( $\mathrm{n}=6$ per group) were ICV infused with CRF at a total (i.e. both ventricles combined) dose of $0 \mu \mathrm{g}, 0.001 \mu \mathrm{g}$ (ca. 0.2 pmol), $0.01 \mu \mathrm{g}$ (ca. $2 \mathrm{pmol}$ ), $0.1 \mu \mathrm{g}$ (ca. $20 \mathrm{pmol}$ ), or $1 \mu \mathrm{g}$ (ca. $0.2 \mathrm{nmol})$. The cannulas were removed (time $=\min 0$ ) and the mouse returned to its home cage and colony room, and retrieved at min 20,60 and 120 for serial blood sampling.

v. Effect of ICV CRF on plasma CRF. Cannulated mice ( $\mathrm{n}=3-4$ per group) were ICV infused with CRF at a dose of $0 \mu \mathrm{g}, 0.1 \mu \mathrm{g}$ or $1 \mu \mathrm{g}$, and 10 min later trunk blood was collected via decapitation.

vi. Effect of ICV or IP astressin X ICV CRF on plasma CORT. Cannulated mice $(\mathrm{n}=6$ per group) were pre-treated with astressin, either ICV infusion (0 or $2 \mu \mathrm{g}$ (ca. $0.6 \mathrm{nmol})$ ) or IP injection ( 0 or $35 \mu \mathrm{g} / \mathrm{kg} / 5 \mathrm{ml}(10 \mathrm{nmol})$ ), and after 15 min were ICV infused with CRF (0 or 0.1 $\mu \mathrm{g})$. The cannulas were removed $($ time $=\min 0)$ and the mouse returned to its home cage and colony room, and retrieved at min 20,60 and 120 for serial blood sampling. To test effects of ICV astressin, groups were icvVEH+icvVEH, icvAST+icvVEH, icvVEH+icvCRF and icvAST+icvCRF. To test effects of IP astressin, groups were ipVEH, ipVEH+icvCRF and ipAST+icvCRF.

vii. Effect of ICV or IP astressin X IP CRF on plasma CORT. Cannulated mice ( $\mathrm{n}=6$ per group) were pre-treated with astressin, either ICV (0 or $2 \mu \mathrm{g})$ or IP injection ( $35 \mu \mathrm{g} / \mathrm{kg} / 5 \mathrm{ml})$, and after 15 min were IP injected with CRF $(0$ or $5 \mu \mathrm{g} / \mathrm{kg} / 5 \mathrm{ml})$. The cannulas were removed (time $=$ $\min 0$ ) and the mouse returned to its home cage and colony room, and retrieved at min 20,60 and 120 for serial blood sampling. To test effects of ICV astressin, groups were icVVEH+ipVEH, icvVEH+ipCRF and icvAST+ipCRF. To test effects of IP astressin, groups were ipVEH+ipCRF and ipAST+ipCRF. 
viii. Effect of ICV or IP astressin X ICV CRF on locomotor activity. Cannulated mice ( $\mathrm{n}=6$ per group) were pre-treated with astressin, either ICV infusion or IP injection, and after 15 min were ICV infused with CRF $(1 \mu \mathrm{g})$. The cannulas were removed and the mouse placed in the activity monitoring apparatus for $50 \mathrm{~min}$. At the end of this period they were blood sampled. To test effects of ICV astressin, groups were icvVEH+icvVEH, icvAST+icvVEH, icvVEH+icvCRF and icvAST+icvCRF. To test effects of IP astressin, groups were ipVEH+icvVEH, ipVEH+icvCRF and ipAST+icvCRF.

\subsection{RIA of ACTH and corticosterone and fluorescent EIA of CRF, in plasma}

Immunoreactive (ir) ACTH in mouse plasma was measured using a radioimmunoassay (RIA) kit for direct determination of human ACTH in EDTA plasma (DiaSorin, Stillwater, MN, USA). We had previously adapted and validated the kit for use with rat EDTA plasma without extraction (Pryce et al., 2003). The assay principle was competitive, equilibrium RIA, with an antiserum of rabbit anti-ACTH, ${ }^{125} \mathrm{I}-\mathrm{ACTH}$ as trace, and goat anti-rabbit serum as precipitating complex. For plasma samples from Expts (i), (ii) and (vii), EDTA-plasma pools were used to validate the kit for use with these samples, in terms of parallelism and accuracy. A single ACTH determination per sample was conducted using $25 \mu \mathrm{l}$ per RIA tube. All samples per experiment were included in the same assay and intraassay precision was $8.1 \%(n=6)$. For plasma samples from Expts (iii)(iv), validation of the RIA in terms of parallelism and accuracy could not be demonstrated using plasma pools derived from aliquots of these samples.

In samples from Expts (i)-(iv) and (vi), ir CORT was estimated using an in house RIA described previously for rat plasma (Pryce et al., 2001), following validation (parallelism and accuracy) for mouse EDTA plasma. All samples per experiment were included in the same assay in duplicate. Intra-assay precision was $3.6 \%(n=6)$ and inter-assay precision was $4.9 \%(n=6)$. 
Plasma ir CRF was estimated in mouse trunk-blood plasma samples from Expt (v). Plasma samples $(100 \mu \mathrm{l})$ were run through C-18 SEP-columns and eluates were lyophilized over-night. The sample residues were reconstituted in assay buffer, centrifuged, and supernatants were assayed for ir CRF using a CRF fluorescent enzyme immunoassay (EIA) kit (FEK-019-06, Phoenix Pharmaceuticals Inc., Burlingame, CA, USA), validated in-house for mouse plasma. All samples were included in the same assay and intra-assay precision was $11.0 \%(n=6)$.

\subsection{Statistics}

Statistical testing was conducted using SPSS (Version 16), with significance set at $\alpha \leq 0.05$. Data in Expts (i)-(iii) were analysed using General Linear Model repeated measures analysis of variance (ANOVA) with a within-subject factor of Time. Data in Expts (iv)-(vii) were analysed using linear mixed model ANOVA, with a between subject factor of Dose or Group and a within subject factor of Time. Following a significant main effect or interaction effect, post hoc testing was conducted using the Bonferroni test, to control for multiple comparisons. Data are plotted as means and standard deviations.

\section{Results}

\subsection{Expt i. Effect of serial blood sampling (SBS) on plasma ACTH and CORT}

Plasma-ir ACTH and CORT titres in mice exposed to SBS are given in Figure 1A. For $\mathrm{ACTH}$, there was a significant main effect of the repeated measure of Time $(F(3,21)=40.64, p$ $<0.0001)$. Post hoc analysis demonstrated that ACTH titres were greater at min 20 than min 0 $(p<0.004), 60$ and 120 (p's<0.0001). For CORT, there was a significant main effect of the repeated measure of Time $(F(3,21)=18.70, p<0.0001)$. Post hoc analysis demonstrated that CORT titres were greater at $\min 20$ than $\min 0(p<0.001)$ and $120(p<0.04)$, and greater at $\min 60$ than $\min 0$ and 120 (p's < 0.001). 


\subsection{Expt ii. Effect of physical confinement and SBS on plasma ACTH and CORT}

Plasma-ir ACTH and CORT titres in mice exposed to physical confinement + SBS are given in Figure 1B. For ACTH, there was a significant main effect of the repeated measure of Time $(F(3,21)=16.10, p<0.0001)$. Post hoc analysis demonstrated that ACTH titres were greater at $\min 0$ than $\min 60(p<0.01)$ and $120(p<0.002)$, and greater at min 20 than min 60 and 120 (p's < 0.03). For CORT, there was a significant main effect of the repeated measure of Time $(F(3,21)=26.91, p<0.0001)$. Post hoc analysis demonstrated that CORT titres were greater at $\min 20$ than $\min 0(p<0.006), 60(p<0.004)$ and $120(p<0.0001)$, and greater at $\min 60$ than $120(p<0.01)$.

\section{FIGURE 1 ABOUT HERE}

\subsection{Expt iii. Effect of ICV saline infusion and SBS on plasma ACTH and CORT}

Plasma-ir ACTH and CORT titres in mice ICV-infused with saline followed by SBS are given in Figure 2A. For ACTH $(F(2,10)=1.17, p>0.34)$ and $\operatorname{CORT}(F(2,10)=2.92, p>0.10)$ there was no effect of sampling Time on plasma titres, in contrast to the findings of Expts $i$ and ii.

A comparison of titres at the min-20 sampling point in Expts (i)-(iii) is provided in Figure 2B. For ir ACTH, SBS and physical confinement + SBS induced similar mean titres, whereas the mean titre induced by ICV saline infusion was higher. Furthermore, this relatively high titre was maintained until min 120 (Figure 2A), rather than returning to basal titres by min 60 as occurred following SBS and physical confinement + SBS (Figure 1). This marked increase in ir ACTH following ICV saline was not reflected in the mean ir CORT response to ICV saline infusion at $\min 20$ : the latter was similar to the mean CORT titre induced by SBS and less than the mean CORT titre induced by physical confinement + SBS. 


\section{FIGURE 2 ABOUT HERE}

\subsection{Expt iv. Effect of ICV CRF infusion on plasma ACTH and CORT}

For plasma ir ACTH titres following ICV CRF infusion (Figure 3A), there was no significant effect of Dose $(F(4,40)=2.51, p=0.09)$ and a significant main effect of Time $(F(2$, $40)=4.92, p<0.01)$. Post hoc analysis of Time demonstrated that ACTH titres were greater at $\min 20$ than $\min 60(p<0.03)$ and $120(p<0.03)$. For plasma CORT titres (Figure 3B), there was a significant Dose $x$ Time interaction $(F(6,40)=4.49, p<0.001)$ and significant main effects of Dose $(F(4,40)=22.26, p<0.0001)$ and Time $(F(2,40)=12.63, p<0.0001)$. Post hoc analysis of Dose demonstrated that $1 \mu \mathrm{g}$ resulted in greater CORT titres than $\mathrm{VEH}, 0.001 \mu \mathrm{g}$ and $0.01 \mu \mathrm{g}$ (p's $<0.0001$ ), and $0.1 \mu \mathrm{g}$ resulted in greater CORT titres than VEH and $0.001 \mu \mathrm{g}$ (p's < 0.0001). Post hoc analysis of Time demonstrated that CORT titres were greater at min 60 than $\min 120(p<0.0001)$.

It was systematically observed in this experiment that mice infused with $1 \mu \mathrm{g} C R F$ were relatively inactive in their home cage during intervals between blood sampling and were also relatively behaviourally unresponsive during blood sampling.

\section{FIGURE 3 ABOUT HERE}

\subsection{Expt v. Effect of ICV CRF infusion on plasma CRF}

For plasma ir CRF (Figure 4), basal titres were $15-80 \mathrm{pg} / \mathrm{ml}$. Subjects ICV infused with VEH exhibited approximately $100 \mathrm{pg} / \mathrm{ml}$, and ICV CRF infusion resulted in a dose-related

increase, with an approximate 10-fold increase versus VEH with $0.1 \mu \mathrm{g}$ CRF and a proportionate, further 10 -fold increase following $1 \mu \mathrm{g}$ CRF.

FIGURE 4 ABOUT HERE 


\subsection{Expt vi. Effect of pretreatment with ICV or IP astressin on ICV CRF-induced increase}

in plasma CORT

Plasma CORT titres in mice ICV infused with VEH or $0.1 \mu \mathrm{g}$ CRF following pre-treatment with VEH or $2 \mu \mathrm{g}$ ICV astressin, are given in Figure 5A. There was a significant Group x Time interaction $(F(6,34)=11.16, p<0.0001)$ and significant main effects of $\operatorname{Group}(F(3,17)=4.40$, $p<0.02)$ and Time $(F(2,34)=25.55, p<0.0001)$. Post hoc analysis of Time demonstrated that CORT titres were greater at min 20 than $\min 60(p<0.005)$ and $120(p<0.0001)$, and greater at min 60 than min $120(p<0.002)$. A posteriori Group-Time analysis demonstrated that CORT titres were greater in icvVEH/icvCRF mice than in icvVEH/icvVEH mice at min 20 and 60, and icvAST/icvVEH mice at min 20; and were greater in icvAST/icvCRF mice than in icvAST/icvVEH mice at min 20 (Figure 5A). CORT titres were similar in the groups icvVEH/icvCRF and icvAST/icvCRF; therefore, there was no indication that ICV astressin inhibited the increase in plasma CORT induced by ICV CRF.

In order to test whether peripherally administered astressin inhibited ICV CRF-induced increased plasma CORT, mice were pre-treated with VEH or $35 \mu \mathrm{g} / \mathrm{kg}$ astressin and then infused ICV with $0.1 \mu \mathrm{g}$ CRF. Plasma CORT titres are given in Figure 5B. There was a significant Group x Time interaction $(F(2,24)=9.88, p<0.001)$ and significant main effects of Group $(F(1,24)=82.48, p<0.0001)$ and Time $(F(2,24)=13.26, p<0.0001)$. A posteriori Group-Time analysis demonstrated that CORT titers were reduced in ipAST/icvCRF mice relative to ipVEH/icvCRF mice at min 20 and 60 (Figure 5B).

\section{FIGURE 5 ABOUT HERE}

3.7. Expt vii. Effect of pretreatment with ICV or IP astressin on IP CRF-induced increase in plasma CORT. 
This experiment was carried out in order to test whether IP CRF led to increased plasma CORT and whether ICV astressin or IP astressin inhibited the effect of IP CRF on plasma CORT: IP CRF-induced increased plasma CORT that could not be blocked by ICV astressin would provide supportive evidence that the observed ICV CRF-induced increased plasma CORT, that could not be blocked by ICV astressin, was mediated in the periphery. Plasma CORT titres in mice IP injected with CRF (0 or $5 \mu \mathrm{g} / \mathrm{kg}$ ) following pre-treatment with ICV astressin $(0$ or $2 \mu \mathrm{g})$, are given in Figure $6 \mathrm{~A}$. There were significant main effects of Group $(\mathrm{F}(2$, $14)=11.93, \mathrm{p}<0.001)$ and Time $(\mathrm{F}(2,28)=42.26, \mathrm{p}<0.0001)$. Post hoc analysis of Group demonstrated that plasma CORT was significantly increased in icvVEH/ipCRF mice versus icvVEH/icvVEH $(p<0.01)$ mice, and in icvAST/ipCRF mice versus icvVEH/icvVEH mice $(p<$ 0.05), with no significant difference between icvAST/ipCRF and icvVEH/ipCRF mice $(p>0.10)$. Post hoc analysis of Time demonstrated that plasma CORT was significantly increased at min 20 versus $120(p<0.0001)$ and $\min 60$ versus $120(p<0.0001)$.

Plasma CORT titres in mice IP injected with CRF following pre-treatment with IP astressin $(35 \mu \mathrm{g} / \mathrm{kg})$ are given in Figure 6B. There were significant main effects of Group ( $\mathrm{F}(1$, $8)=17.35, \mathrm{p}<0.003)$ and Time $(\mathrm{F}(2,16)=7.57, \mathrm{p}<0.005)$. Plasma CORT titres were significantly decreased in ipAST/ipCRF mice versus ipVEH/ipCRF mice. Post hoc analysis of Time demonstrated that plasma CORT was significantly increased at min 60 versus 120 ( $p<$ 0.004). Because this experiment did not involve ICV infusion, plasma ACTH titres were also measured (Figure 6B). There were significant main effects of Group $(F(1,24)=10.29$, $p<$ 0.004) and Time $(F(2,24)=11.94, p<0.0001)$. Plasma ACTH titres were significantly decreased in ipAST/ipCRF mice versus ipVEH/ipCRF mice. Post hoc analysis of Time demonstrated that plasma ACTH was significantly increased at min 20 versus $60(p<0.04)$ and $120(p<0.0001)$ 


\section{FIGURE 6 ABOUT HERE}

3.8. Expt viii. Effect of pretreatment with ICV or IP astressin on ICV CRF-induced decrease in locomotor activity

Given the absence of an effect of ICV astressin on the ICV CRF readout of plasma CORT, we investigated for a central effect of astressin in terms of whether ICV astressin could inhibit the ICV CRF-induced decreased locomotor activity observed in Expt. iv. Locomotor activity of mice infused with ICV VEH or astressin $(2 \mu \mathrm{g})$ followed by ICV VEH or CRF $(1 \mu \mathrm{g})$ are given in Figure 7A. There were significant main effects of $\operatorname{Group}(F(3,17)=5.30, p<0.009)$ and Time $(F(9,153)=16.40, p<0.0001)$. Post hoc analysis of Time demonstrated that distance moved during min 1-5 (overall mean $\pm S D=1194 \pm 325$ arbitrary units, $n=21$ ) was greater than in each other 5-min block (e.g. min 6-10, $609 \pm 403$ arbitrary units) (p's < 0.004), and that there were no further time-block differences. Post hoc analysis of Group demonstrated that distance moved was greater in AST/CRF mice than VEH/CRF mice $(p<0.05)$ and in AST/VEH mice than VEH/CRF mice $(p<0.01)$. In blood samples taken immediately after removal of the mice from the activity chambers, there was a significant Group effect on plasma CORT titres $(F(3,17)=32.98, p<0.0001$; Figure $7 B)$ with titres greater in $V E H / C R F$ than VEH/VEH and AST/VEH mice ( $p$ 's < 0.0001), and greater in AST/CRF than VEH/VEH and AST/VEH mice ( $p$ 's < 0.0001), and no significant difference between AST/CRF and VEH/CRF mice.

We also tested whether IP astressin could inhibit ICV CRF-induced decreased locomotor activity: a lack of effect would provide supportive evidence that this effect of astressin was centrally-mediated. Distances moved in mice pre-treated with IP astressin ( 0 or $35 \mu \mathrm{g} / \mathrm{kg}$ ) followed by ICV CRF (0 or $1 \mu \mathrm{g}$ ) are given in Fig 7C. There were significant main effects of Group $(F(2,9)=16.44, p<0.001)$ and Time $(F(9,81)=12.66, p<0.0001)$. Post hoc analysis of 
Group demonstrated that distance moved was significantly reduced in ipVEH/icvCRF versus ipVEH/icvVEH $(p<0.04)$ and in ipAST/icvCRF versus ipVEH/icvVEH $(p<0.01)$, with no significant difference between ipAST/icvCRF and ipVEH/icvCRF $(p=1)$ (Figure 7C).

\section{FIGURE 7 ABOUT HERE}

\section{Discussion}

The current experiments carried out with C57BL/6 mice demonstrate that: (1) ICV saline infusion led to a marked, sustained increase in immunoreactive plasma ACTH and a mild increase in plasma CORT, relative to the respective increases induced by physical confinement and serial blood sampling. (2) ICV CRF infusion at $0.001-1 \mu \mathrm{g}$ induced no further increase in plasma ACTH versus vehicle, and induced dose-dependent increases in plasma CORT. ICV CRF at $1 \mu \mathrm{g}$ also reduced home cage locomotor activity. (3) ICV CRF induced dose-dependent increases in plasma CRF. (4) ICV astressin failed to block ICV CRF-induced increased plasma CORT, whereas IP astressin did do so. (5) ICV astressin failed to block IP CRF-induced increased plasma CORT, whereas IP astressin did do so, as well as blocking IP CRF-induced increased plasma ACTH. (6) ICV CRF-induced locomotor inactivity was blocked by ICV astressin, but not by IP astressin.

In demonstrating the dose-dependent effect of ICV CRF on plasma CORT levels the present study provides similar findings to those reported for the rhesus macaque, in which 1 and 10 $\mu \mathrm{g} / \mathrm{kg}$ ICV CRF yielded increased plasma cortisol levels (Rock et al. 1984). In the rat, a study of intra-venous CRF demonstrated that $0.1-10 \mu \mathrm{g}$ yielded dose-dependent increases in plasma ACTH but dose-independent increases in plasma CORT (Rivier et al. 1982). In a pilot study that we carried out in Lister-hooded rat to establish the methodology for this mouse study, ICV CRF at $0.1,1$ and $10 \mu \mathrm{g}$ yielded dose-dependent increases in plasma ACTH and CORT (unpublished 
data). In mouse, a previous study in C57BL/6N mice with $0.1-1 \mu \mathrm{g} / \mathrm{kg}$ ICV CRF demonstrated dose-independent increases in plasma CORT (Warnock et al. 2009).

The experiments (i, ii, iii) with serial blood sampling (SBS), confinement in a novel tube and SBS, and ICV saline infusion, were carried out to establish the magnitude and time course of the plasma ACTH-CORT responses to moderate stressors and to biologically validate the immunoassays for ACTH and CORT in this mouse strain. For plasma ACTH, levels were highest within the first $20 \mathrm{~min}$ following physical confinement/SBS onset followed by a monotonic decline and a return to basal levels. For plasma CORT, the maximum mean level was at min 20-60 post-stressor followed by a monotonic decline. Therefore, stress responses were detectable for both plasma ACTH and CORT and, as expected, the ACTH peak preceded the CORT peak. In contrast, when ICV saline was the stressor, there was a relatively marked increase in plasma ACTH immunoreactivity at min 20 and this was maintained until min 120. Plasma CORT exhibited only a mild increase, strongly suggesting that ICV saline infusion was a mild stressor. One possible explanation for this marked increase in plasma ACTH immunoreactivity as measured in the RIA is that the solution injected ICV ( $3 \mu$ in total) led to a mechanical displacement of cerebrospinal fluid/injected fluid into the pituitary, which in turn induced washing out of pituitary peptides into the blood, including peptides that cross-react in the ACTH RIA. Candidates would include proopiomelanocortin (POMC), a-melanocyte stimulating hormone $\left(\mathrm{MSH}, \mathrm{ACTH}_{1-13}\right)$ and corticotropin-like intermediary lobe peptide (CLIP, $\mathrm{ACTH}_{18-39}$ ). The cross-reactivity of these non-ACTH peptides with the RIA kit antibody used is unknown, but in other ACTH assays, even in specific two-site immunoradiometric assays, it has been demonstrated that CLIP cross-reactivity can be marked and that MSH and POMC impedance of ACTH binding also can occur (e.g. (Guiban et al. 2001)). These experiments demonstrate that plasma ir-ACTH determinations would not be a valid marker of ICV CRF 
effects. There was no evidence to indicate that plasma CORT would not provide a valid marker; in fact, the ICV infusion procedure led to only a mild increase in plasma CORT.

In the ICV CRF expt (iv), even at $1 \mu \mathrm{g}$ CRF there was no consistent increase in ir-ACTH relative to saline, suggesting a floor-effect in the method, as discussed above. For plasma CORT, there was a dose-dependent increase in response to ICV CRF, with doses of 0.1 and $1 \mu \mathrm{g}$ yielding a significant increase. The increase was maximal at $\min 60$ and the longevity of the increase was also dose-dependent. At $0.1 \mu \mathrm{g}$ the absolute levels and the time profile of the plasma CORT response were similar to those observed following the SBS and physical confinement stressors. These dose-dependent findings strongly suggest that plasma CORT provides an accurate marker for ICV CRF infusion in mouse, in agreement with previous studies e.g. (Warnock et al. 2009). Because of the low solubility of astressin in artificial CSF (see below), neither CRF nor astressin was administered in aCSF (CRF was infused in saline and astressin in water). ICV CRF was administered in saline in a number of previous ICV CRF rodent studies e.g. (Bittencourt and Sawchenko 2000; Warnock et al. 2009). To check that the current findings with ICV CRF were not specific to saline vehicle, we also repeated the ICV CRF experiment using aCSF as vehicle and obtained the same findings (unpublished data). What requires clarification is the pathway via which ICV CRF leads to dose-dependent increases in plasma CORT.

To attempt to gain insight into this pathway was the rationale for measuring ir-CRF levels in whole-blood plasma at $10 \mathrm{~min}$ following ICV CRF infusion (expt v). There was a dosedependent increase in plasma CRF levels at 0.1 and $1 \mu \mathrm{g} \mathrm{ICV} \mathrm{CRF} \mathrm{relative} \mathrm{to} \mathrm{basal} \mathrm{and} \mathrm{ICV}$ VEH infusion levels, which were approximately $100 \mathrm{pg} / \mathrm{ml}$. Assuming that the majority of this increase was accounted for by exogenous CRF, these data are consistent with the passage of exogenous CRF from the ventricles into the pituitary and the peripheral circulation. At the 
pituitary, the exogenous CRF would stimulate ACTH release. Given the lack of robust evidence for an ICV CRF-induced plasma ACTH increase, it is possible that ICV CRF entered the periphery and acted directly at the adrenal gland to stimulate CORT secretion. However, this is unlikely given the evidence for a complete lack of effect of IV CRF on CORT levels in hypophysectomized rats (Rivier et al. 1982). Further supportive evidence for the interpretation that the ICV CRF-induced increase in plasma CORT was indeed mediated in the periphery and by increased ACTH was provided by the ICV and IP astressin experiments, as discussed below.

Astressin is a potent antagonist at CRF R1 $\left(\mathrm{K}_{\mathrm{i}}=12 \mathrm{nM}\right)$ and CRF R2 $\left(\mathrm{K}_{\mathrm{i}}=1.5 \mathrm{nM}\right)$. It inhibits ACTH secretion in vitro and, following IV infusion, in vivo (Steckler and Dautzenberg 2006). Relative to other CRF R1/R2 antagonists, e.g. ahelCRF ${ }_{9-41}$, astressin has low solubility in artificial CSF (Brauns et al. 2001). It has been proposed that low solubility in CSF could reduce the antagonistic efficacy of ICV astressin in in vivo readouts: For example, in BALB/c mice, 0.3 $\mu \mathrm{g} \mathrm{ICV}$ astressin did not reduce anxiety on the elevated plus maze (Brauns et al. 2001). In rat, 5 $\mu \mathrm{g}$ ICV astressin was required to antagonize the anxiogenic effect of $0.5 \mu \mathrm{g}$ ICV CRF on the elevated plus maze (Spina et al. 2000), and a dose of $10 \mu \mathrm{g}$ ICV astressin was required to partially inhibit the increase in plasma ACTH induced by $4 \mu \mathrm{g} / \mathrm{kg}$ IV CRF (Rivier et al. 1996); an IV dose of $300 \mu \mathrm{g} / \mathrm{kg}$ astressin inhibited the increase in plasma ACTH induced by $4 \mu \mathrm{g} / \mathrm{kg} \mathrm{IV}$ CRF (Rivier et al. 1996).

In the present study (expt vi), $2 \mu \mathrm{g} \mathrm{ICV}$ astressin was without effect on the increase in plasma CORT levels induced by $0.1 \mu \mathrm{g}$ ICV CRF. Astressin administered IP did antagonize the ICVCRF induced plasma CORT increase. Together, these findings strongly suggest that ICV CRF exerted its effect on plasma CORT in the periphery and, in contrast to CRF, that astressin, at the dose used, did not pass through the ventricles into the circulation and pituitary. Similarly, when CRF was administered IP (expt vii) the observed increase in plasma CORT was not 
antagonized by ICV astressin but was antagonized by IP astressin. In the IP astressin/IP CRF experiment, both plasma ACTH and CORT were increased by CRF and antagonized by astressin, suggesting that the similar increases observed in plasma CORT following ICV CRF were also mediated by increased plasma ACTH. Therefore, several lines of evidence of this mouse study are consistent with ICV CRF exerting its effects on plasma CORT levels at the level of the pituitary and, therefore, that plasma CORT does not constitute either a suitable marker of ICV CRF activity in the CNS or the antagonism of this central activity by CRF R1/2 antagonism. The rationale for this study was to provide evidence of pathways via which exogenous CRF stimulates CORT and impacts on behaviour, thereby identifying readouts for the study of CRF-R antagonists on CRF-induced effects. In the course of the study it was demonstrated that the procedures used, e.g. ICV infusion, per se caused consistent increases in plasma CORT and, although not studied here, it would be of interest to investigate whether these responses, which quite possibly are mediated by increased endogenous CRF/urocortin, are also blocked by astressin, either given IP or ICV.

In contrast to a lack of effect on the increase in plasma CORT levels induced by ICV CRF, $2 \mu \mathrm{g}$ ICV astressin did antagonize the inhibitory effect of $1 \mu \mathrm{g}$ ICV CRF on locomotion (expt vii). This effect was independent of plasma CORT: ICV AST/ICV CRF mice exhibited increased plasma CORT levels but normal levels of locomotion. That this effect of ICV astressin was indeed mediated directly centrally was indicated by the lack of effect of IP astressin on ICV CRF induced hypo-locomotion (expt viii). The locomotion test was performed as a simple readout for ICV CRF behavioural effects and the effects of CRF $R$ antagonism thereon, based on the consistent observation of hypo-activity of mice in the home cage following $1 \mu \mathrm{g} \mathrm{ICV} \mathrm{CRF.} \mathrm{It} \mathrm{is}$ well-established in rat that ICV CRF leads to increased locomotor activity in a familiar cage and decreased activity in a novel open field (Koob et al. 1993; Sutton et al. 1982). In CD-1 albino 
mice, $0.1 \mu \mathrm{g}$ ICV CRF led to decreased activity in a novel open field and increased time spent in the centre of the open field related to a delay in leaving the centre after being placed there at the onset of the test (Swiergiel et al. 2008). In our study the test apparatus was not novel to the mice: we performed two habituation sessions in an attempt to increase the similarity of the response to the hypo-locomotion in the home cage observed in response to $1 \mu \mathrm{g}$ ICV CRF. Given that ICV CRF penetrates throughout the rodent brain into a number of regions expressing CRF R1 and/or R2, as demonstrated using FOS expression in rat (Bittencourt and Sawchenko 2000) and local cerebral glucose utilization in mouse (Warnock et al. 2009), for example, then it is parsimonious to avoid speculation on the emotional-motivational state induced by $1 \mu \mathrm{g} \mathrm{ICV}$ CRF and underlying the consistent reduction in locomotor activity observed. Nonetheless, this consistent reduction in locomotor activity provides a basic readout for ICV CRF central activity as well as for the centrally-mediated antagonism of this behavioural readout by CRF R antagonism. It is unclear from the current data whether this behavioural effect of ICV CRF is mediated and antagonized via CRF R1 and/or R2.

The present findings can be compared to those reported for mice manipulated genetically to over-express CRF in the brain. Non-conditional transgenic over-expression of the CRF gene would, in broad terms, be expected to result in a chronic form of what ICV CRF appeared to induce acutely in the current experiments, namely increased central and peripheral CRF levels. Such mice do indeed exhibit increased basal plasma ACTH and CORT levels relative to wildtype mice, and reduced locomotor activity, at least in a novel environment (Stenzel-Poore et al. 1992; Stenzel-Poore et al. 1994). Conditional transgenic mice that over-express CRF in the forebrain specifically did not exhibit altered basal plasma ACTH and CORT levels relative to wildtype. This was the case despite a strong decrease in endogenous CRF expression in the hypothalamic PVN, from which reduced basal ACTH and CORT levels would be expected (Lu et al. 2008). Based on the current findings it would be worthwhile to measure plasma CRF levels in 
such conditional CRF over-expressing mice, given that any increased transfer from the brain to the periphery could act on pituitary corticotrophs directly.

Therefore, this study has provided evidence that, in BL/6 mice, ICV CRF induces a dosedependent increase in plasma CORT via a peripheral pathway and a reduction in locomotion via a central pathway. It has provided evidence for a double dissociation of the ability of astressin to antagonize these effects relative to its route of administration: only IP astressin antagonized the ICV CRF induced increase in plasma CORT and only ICV astressin antagonized the ICV CRF induced decrease in locomotion. Given that the lack of effect of ICV astressin on plasma CORT was demonstrated using a single dose only, then it can of course not be concluded that ICV astressin at higher doses would not reduce plasma CORT responses to ICV CRF. Nonetheless, the crucial point to note here is that the dose of ICV astressin that did not antagonize the effect of ICV CRF on plasma CORT did antagonize the effect of ICV CRF on motor activity. As such, the preparation described here could be used to provide initial indications on the central and peripheral activity of CRF-R antagonists, including pharmacokinetics following peripheral administration.

\section{Disclosures}

All authors were full time employees of Novartis Pharma AG, Basel, Switzerland during the conducting of the experiments described, and RM, GR and KHM were full time employees of Novartis Pharma AG, Basel, Switzerland at the time this manuscript was submitted for review.

\section{Acknowledgements}


We are extremely grateful to Roger Trudi for animal care and to Markus Fendt, Hugo Buerki, Frederique Chaperon and Melanie Ceci for technical assistance, and Eckhard Weber for discussion.

\section{References}

Bittencourt, J.C., Sawchenko, P.E., 2000. Do centrally administered neuropeptides access cognate receptors? an analysis in the central corticotropin-releasing factor system. J. Neurosci. 20, 1142-1156.

Brauns, O., Liepold, T., Radulovic, J., Spiess, J., 2001. Pharmacological and chemical properties of astressin, antisauvagine-30 and a-helCRF: significance for behavioral experiments. Neuropharmacology 41, 507-516.

Franklin, K.B.J., Paxinos, G., 2008. The Mouse Brain: in stereotaxic coordinates, Compact 3rd edn. New York, Academic Press.

Guiban, D., Massias, J-F., Dugue, M-A., Coste, J., Bertagna, X., Raffin-Sanson, M-L., 2001. A new generation IRMA for ACTH with improved specificity: validation in various physiological and pathological conditions. Eur. J. Endocrinol. 144, 369-377.

Koob, G.F., Heinrichs, S.C., Pich, E.M., Menzaghi, F., Baldwin, H., Miczek, K., Britton, K.T., 1993. The role of corticotropin-releasing factor in behavioural responses to stress Corticotropin-Releasing Factor. Ciba Foundation Symposium 172. Wiley, Chichester, pp 277-295.

Lu, A., Steiner, M.A., Whittle, N., Vogl, A.M., Walser, S.M., Ableitner, M., Refojo, D., Ekker, M., Rubenstein, J.L., Stalla, G.K., Singewald, N., Holsboer, F., Wotjak, C.T., Wurst, W., Deussing, J.M., 2008. Conditional mouse mutants highlight mechanisms of corticotropinreleasing hormone effects on stress-coping behavior. Mol. Psychiatry 13, 1028-1042. 
Pryce, C.R., Bettschen, D., Nanz-Bahr, N.I., Feldon, J., 2003. Comparison of the effects of early handling and early deprivation on conditioned stimulus, context, and spatial learning and memory in adult rats. Behav. Neurosci. 117, 883-893.

Rivier, C., Brownstein, M., Spiess, J., Rivier, J., Vale, W., 1982. In vivo corticotropin-releasing factor-induced secretion of adrenocorticotropin, B-endorphin, and corticosterone. Endocrinology 110, 272-278,

Rivier, C., Rivier, J., Lee, S. 1996. Importance of pituitary and brain receptors for corticotrophinreleasing factor in modulating alcohol-induced ACTH secretion in the rat. Brain Res. 721, 83-90.

Rock, J.P., Oldfield, E.H., Schulte, H.M., Gold, P.W., Kornblith, P.L., Loriaux, L., Chrousos, G.P., 1984. Corticotropin releasing factor administered into the ventricular CSF stimulates the pituitary-adrenal axis. Brain Res. 323, 365-368.

Spina, M.G., Basso, A.M., Zorrilla, E.P., Heyser, C.J., Rivier, J., Vale, W., Merlo-Pich, E., Koob, G.F., 2000. Behavioral effects of central administration of the novel CRF antagonist astressin in rats. Neuropsychopharmacol. 22, 230-239.

Steckler, T., Dautzenberg, F.M. 2006. Corticotropin-releasing factor receptor antagonists in affective disorders and drug dependence - an update. CNS \& Neurolog. Disorders Drug Targets 5, 147-165.

Stenzel-Poore, M.P., Cameron, V.A., Vaughan, J., Sawchenko, P.E., Vale, W., 1992. Development of Cushing's syndrome in corticotropin-releasing factor transgenic mice. Endocrinology 130, 3378-3386.

Stenzel-Poore, M.P., Heinrichs, S.C., Rivest, S., Koob, G.F., Vale, W.W., 1994. Overproduction of corticotropin-releasing factor in transgenic mice: a genetic model of anxiogenic behavior. J. Neurosci. 14, 2579-2584. 
Sutton, R.E., Koob, G.F., Le Moal, M., Rivier, J., Vale, W., 1982. Corticotropin releasing factor produces behavioural activation in rats. Nature 297, 331-333.

Swanson, L.W., Sawchenko, P.E., Rivier, J., Vale, W.W., 1983. Organization of ovine corticotropin-releasing factor immunoreactive cells and fibers in the rat brain: an immunohistochemical study. Neuroendocrinology 36, 165-186.

Swiergiel, A.H., Leskov, I.L., Dunn, A.J., 2008. Effects of chronic and acute stressors and CRF on depression-like behavior in mice. Behav. Brain Res. 186, 32-40.

Turnbull, A.V., Vaughan, J., Rivier, J.E., Vale, W.W., Rivier, C. 1999. Urocortin is not a significant regulator of intermittent electrofootshock-induced adrenocorticotropin secretion in the intact male rat. Endocrinology 140, 71-78.

Vale, W., Spiess, J., Rivier, C., Rivier, J., 1981. Characterization of a 41-residue ovine hypothalamic peptide that stimulates secretion of corticotropin and B-endorphin. Science 213, 1394-1397.

Van Pett, K., Viau, V., Bittencourt, J.C., Chan, R.K.W., Li, H-Y., Arias, C., Prins, G.S., Perrin, M., Vale, W., Sawchenko, P.E., 2000. Distribution of mRNAs encoding CRF receptors in brain and pituitary of rat and mouse. J. Comp. Neurology 428, 191-212.

Warnock, G., Moechars, D., Langlois, X., Steckler, T., 2009. In vivo evidence for ligand-specific receptor activation in the central CRF system, as measured by local cerebral glucose utilization. Peptides 30, 947-954.

Figure legends

Figure 1. Plasma titres of ACTH (filled squares) and CORT (open circles) in naive C57BL/6 mice, (A) across serial tail-vein blood sampling at min 0, 20, 60 and 120, (B) following 5-min confinement in a novel environment (transparent plastic tube; indicated by grey bar) + serial blood sampling at min 20,60 and 120. In (B), values at time point 0 min were measured in blood samples collected from a separate group of naive mice immediately following removal from the 
home cage. In (A) and (B), values are mean+/-SD for $n=8$. Data points denoted by different letters are significantly different in post hoc pairwise comparisons, upper case for ACTH and lower case for CORT.

Figure 2. (A) Plasma titres of ACTH (filled squares) and CORT (open circles) in cannulated mice infused ICV with saline (indicated by grey bar) and serially blood sampled. Values at time point 0 min were measured in blood samples collected from a separate group of naive mice immediately following removal from the home cage. Values are mean $+/-S D$ for $n=6$. There was no significant effect of sample time following ICV saline for ACTH or CORT. (B) Visual comparison of plasma ACTH and CORT titres following different stressors: basal titres; at min 20 following blood sampling at min 0 ; at min 20 following physical confinement at min 1-5; at min 20 following ICV saline infusion at min 1-5.

Figure 3. In cannulated C57BL/6 mice, effect of various doses of bilateral ICV CRF on plasma titres of (A) ACTH and (B) CORT. Serial tail-vein blood samples were obtained at min 20,60 and 120 post-CRF infusion from mice kept in their home cage/room. Values are mean+SD for $n$ = 5-6 per group. Doses denoted by different letters yielded significantly different plasma CORT titres in post hoc pairwise comparisons.

Figure 4. In cannulated C57BL/6 mice, effects of ICV or IP saline (VEH) or ICV CRF on plasma titres of CRF. Values are individual data points for mice from which trunk blood was collected either immediately after removal from the home cage (Basal, $n=3$ ), 10 min after ICV infusion of $\operatorname{VEH}(n=4), 0.1 \mu g \operatorname{CRF}(n=3)$ or $1 \mu g \operatorname{CRF}(n=3)$, or IP VEH injection $(n=3)$.

Figure 5. In cannulated C57BL/6 mice, effects of prior treatment with (A) bilateral ICV astressin (2 $\mu \mathrm{g}$ in $4 \mu \mathrm{l})$ or (B) IP astressin $(35 \mu \mathrm{g} / \mathrm{kg})$, on bilateral ICV CRF $(0.1 \mu \mathrm{g}$ in $3 \mu \mathrm{l})$ induction of increased plasma CORT titres. Serial tail-vein blood samples were obtained at min 20, 60 and 
120 post-CRF infusion. Values are mean+SD for $n=5-6$ mice per group. ${ }^{*} p<0.05,{ }^{* *} p<0.01$ for post hoc pairwise comparisons of data points.

Figure 6. (A) In cannulated C57BL/6 mice, effects of prior treatment with bilateral ICV astressin (2 $\mu \mathrm{g}$ in $4 \mu \mathrm{l})$ on IP CRF $(5 \mu \mathrm{g} / \mathrm{kg})$ induction of increased plasma CORT titres. (B) In noncannulated C57BL/6 mice, effects of prior treatment with IP astressin $(35 \mu \mathrm{g} / \mathrm{kg})$ on IP CRF (5 $\mu \mathrm{g} / \mathrm{kg}$ ) induction of increased plasma CORT and ACTH titres. Serial tail-vein blood samples were obtained at $\min 20,60$ and 120 post-CRF infusion. Values are mean+SD for $n=5-6$ mice per group. Treatment groups denoted by different letters yielded significantly different plasma CORT or ACTH titres.

Figure 7. (A) In cannulated C57BL/6 mice, effects of prior treatment with bilateral ICV astressin $(2 \mu \mathrm{g}$ in $4 \mu \mathrm{l})$ on ICV CRF $(1 \mu \mathrm{g}$ in $3 \mu \mathrm{l})$ induction of locomotor hypoactivity. The graph depicts the treatment group overall mean+SD per 50 min test for $n=5-6$ animals per group. Treatment groups depicted by different letters exhibited significantly different locomotor activity. (B) For the same mice, effects of ICV astressin and ICV CRF on plasma CORT titres (mean+SD) in blood samples collected immediately after the 50-min activity test. Treatment groups depicted by different letters exhibited significantly different plasma CORT titres. (C) In cannulated C57BL/6 mice, effects of prior treatment with IP astressin $(35 \mu \mathrm{g} / \mathrm{kg})$ on ICV CRF $(1 \mu \mathrm{g}$ in $3 \mu \mathrm{l})$ induction of locomotor hypoactivity. Values are mean+SD for $n=4$ mice per group. Treatment groups depicted by different letters exhibited significantly different locomotor activity. 
Click here to download Figure(s): Figure_1.ppt

Figure 1

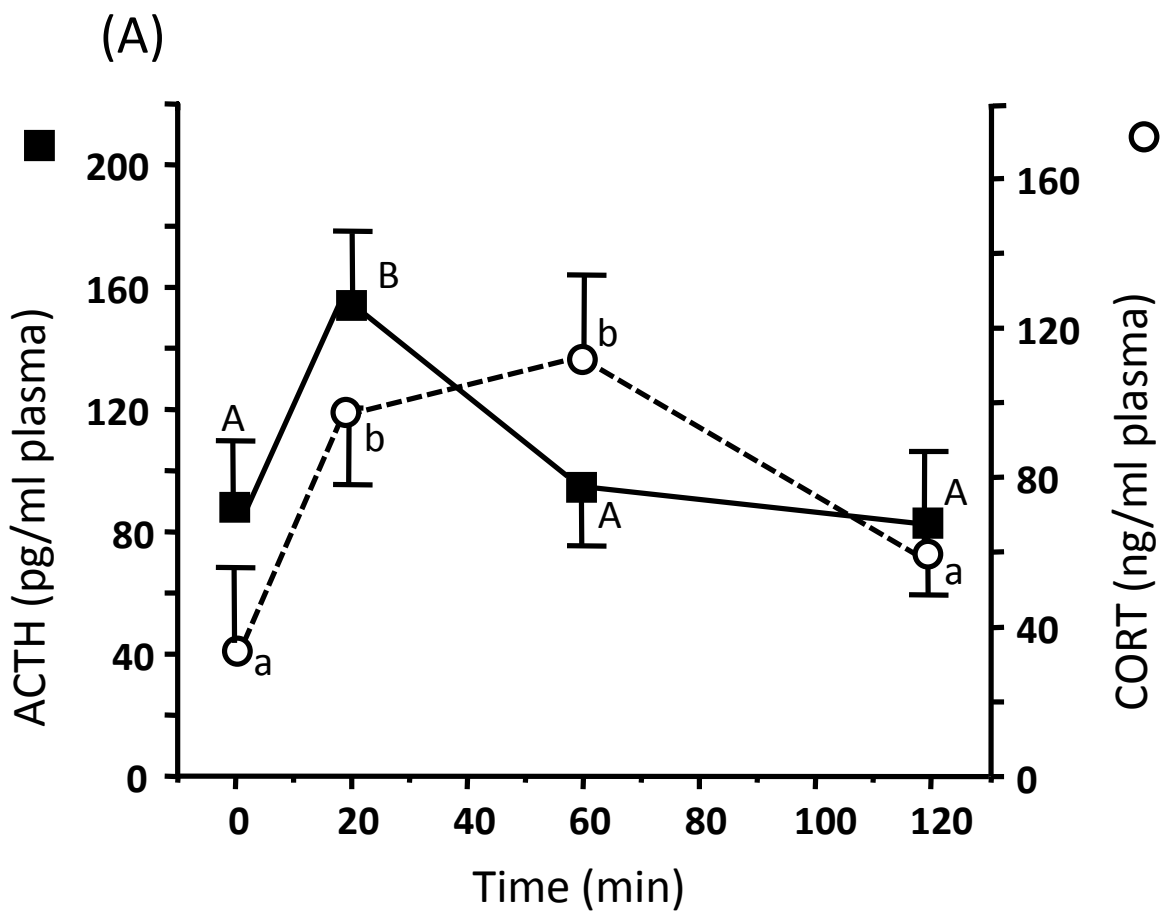

(B)

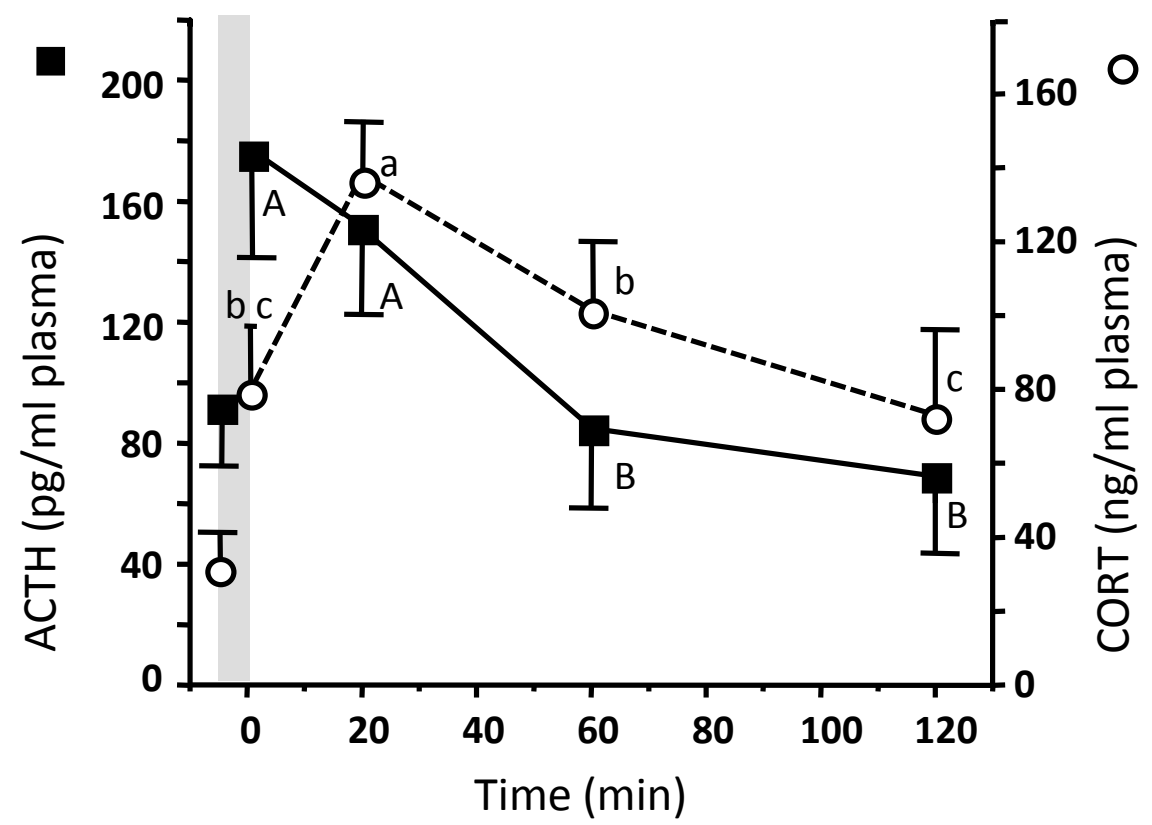


Click here to download Figure(s): Figure_2.ppt

Figure 2

(A)

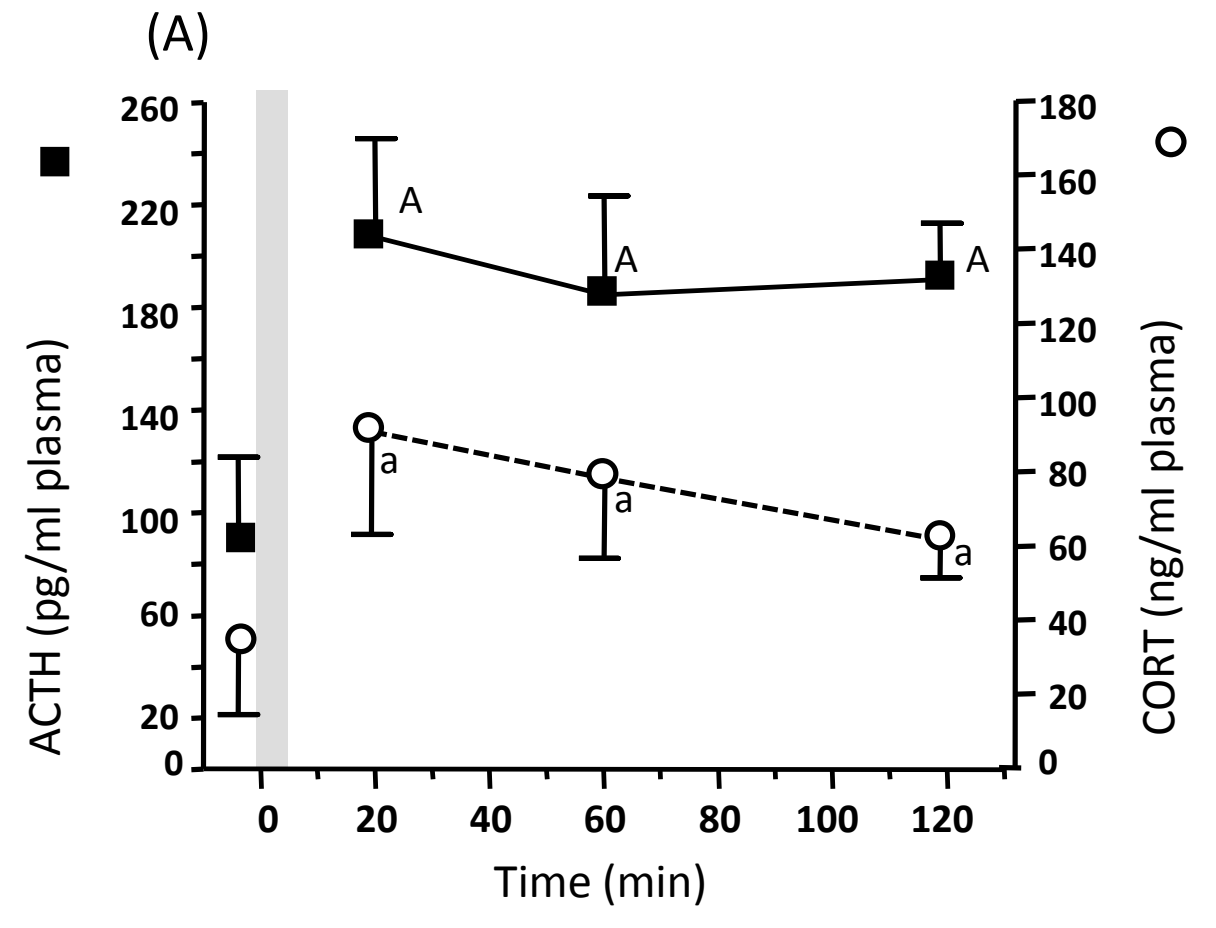

(B)
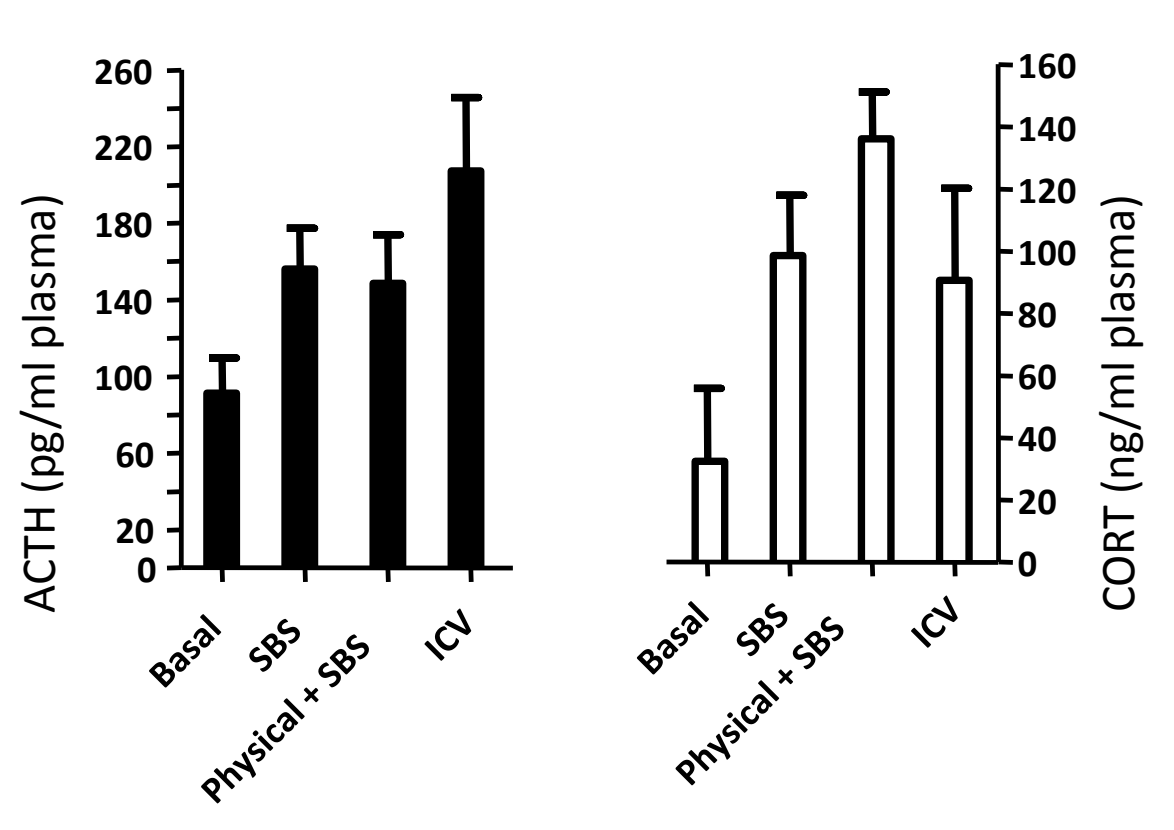
Figure(s)

Click here to download Figure(s): Figure_3.ppt

Figure 3

(A)

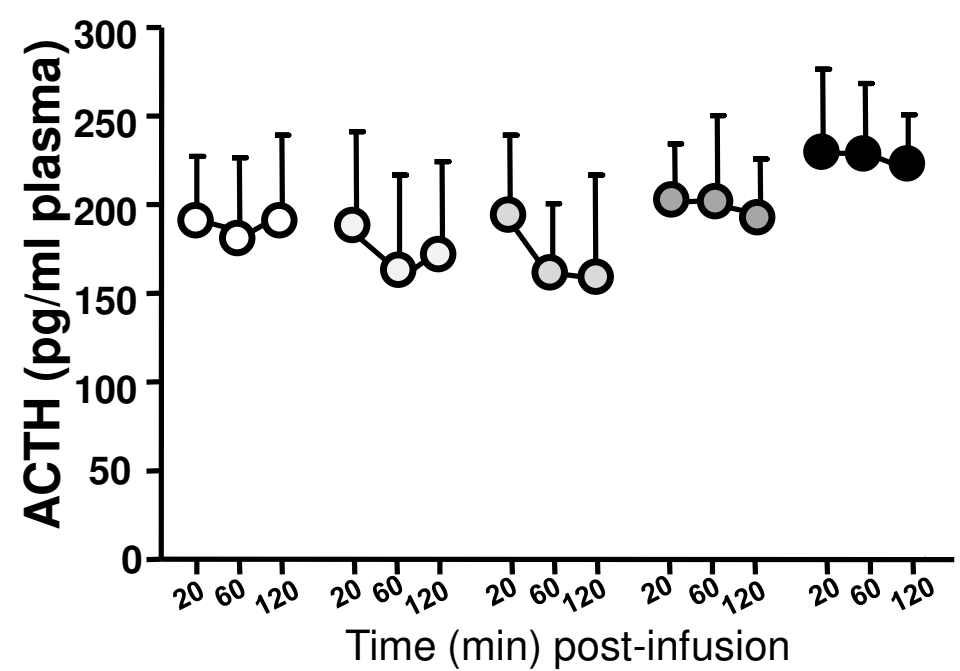

VEH

(5)
0.001

(5)
0.01

CRF $(\mu \mathrm{g}$ ICV)
(B)

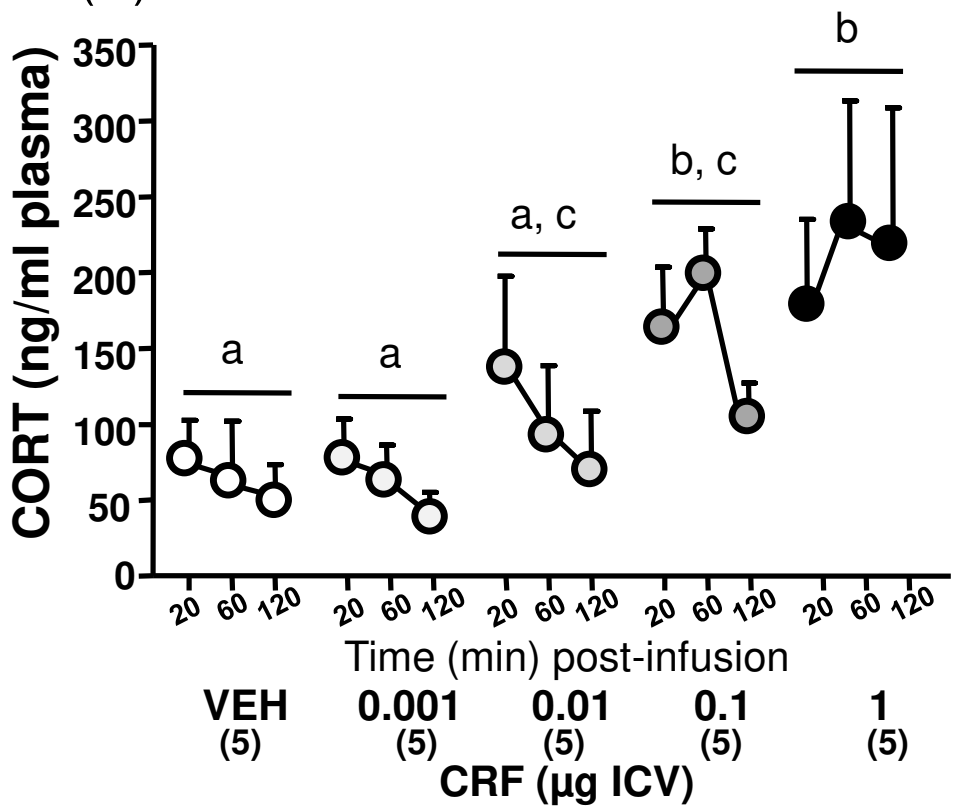

1 
Click here to download Figure(s): Figure_4.ppt

Figure 4

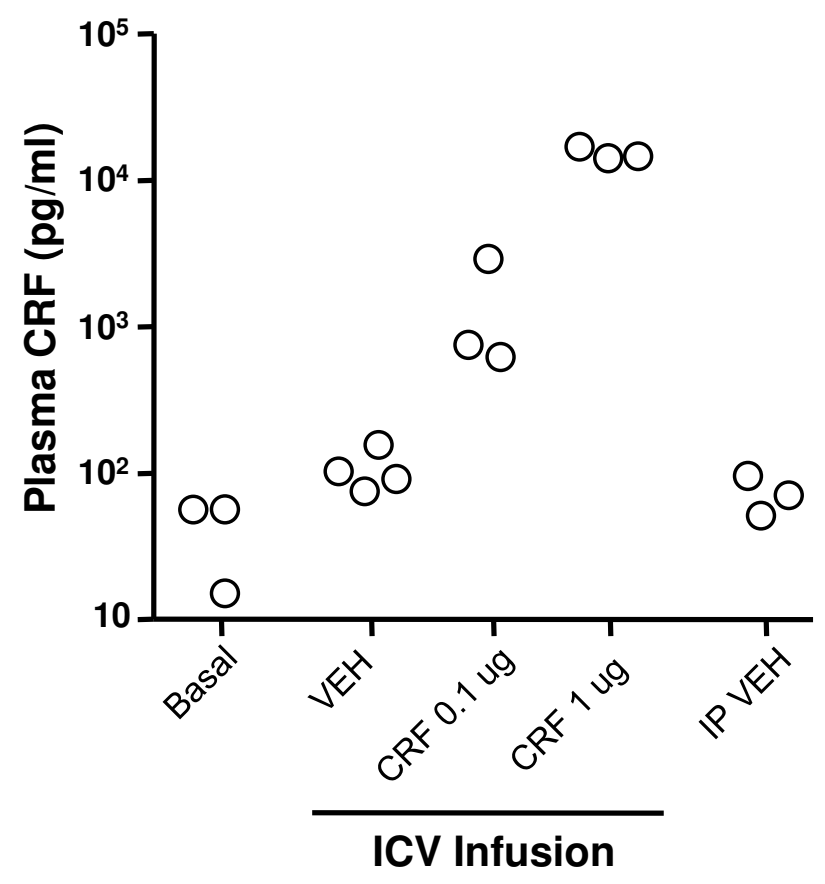


Click here to download Figure(s): Figure_5_Rev.ppt

Figure 5
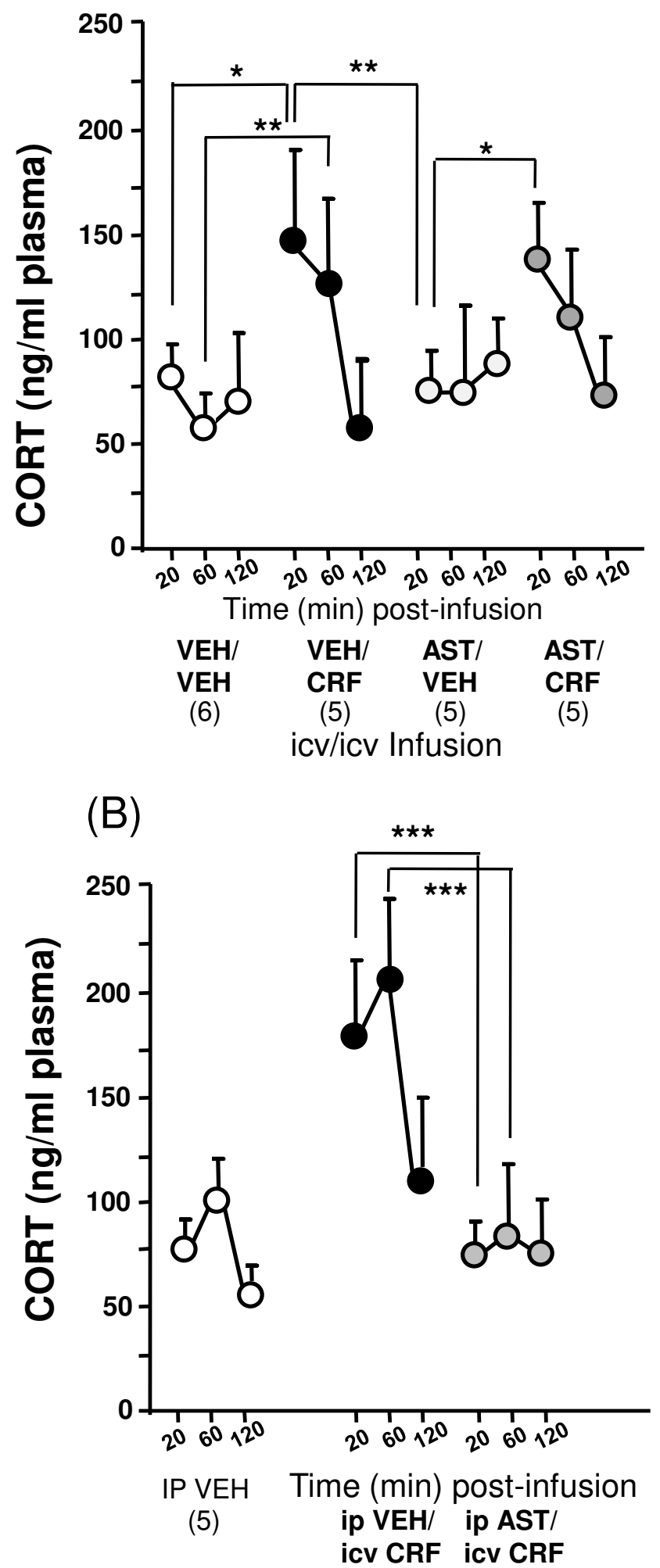

(5)

(5) 


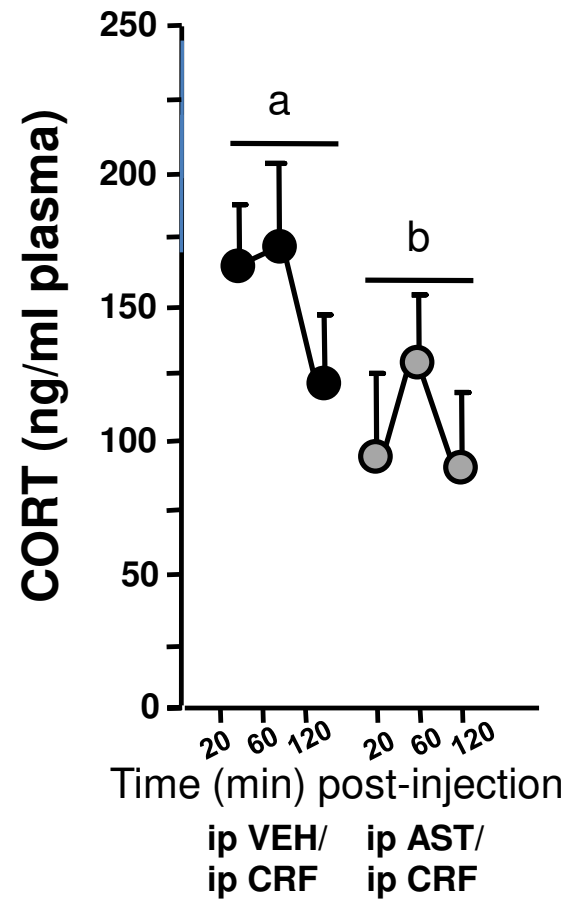

(5)

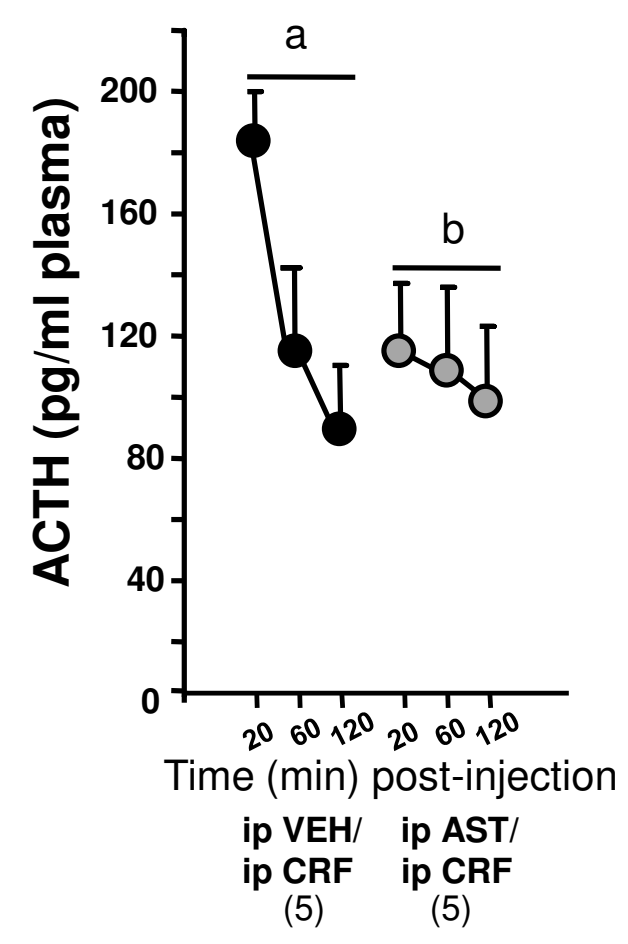

(5)
Figure 6

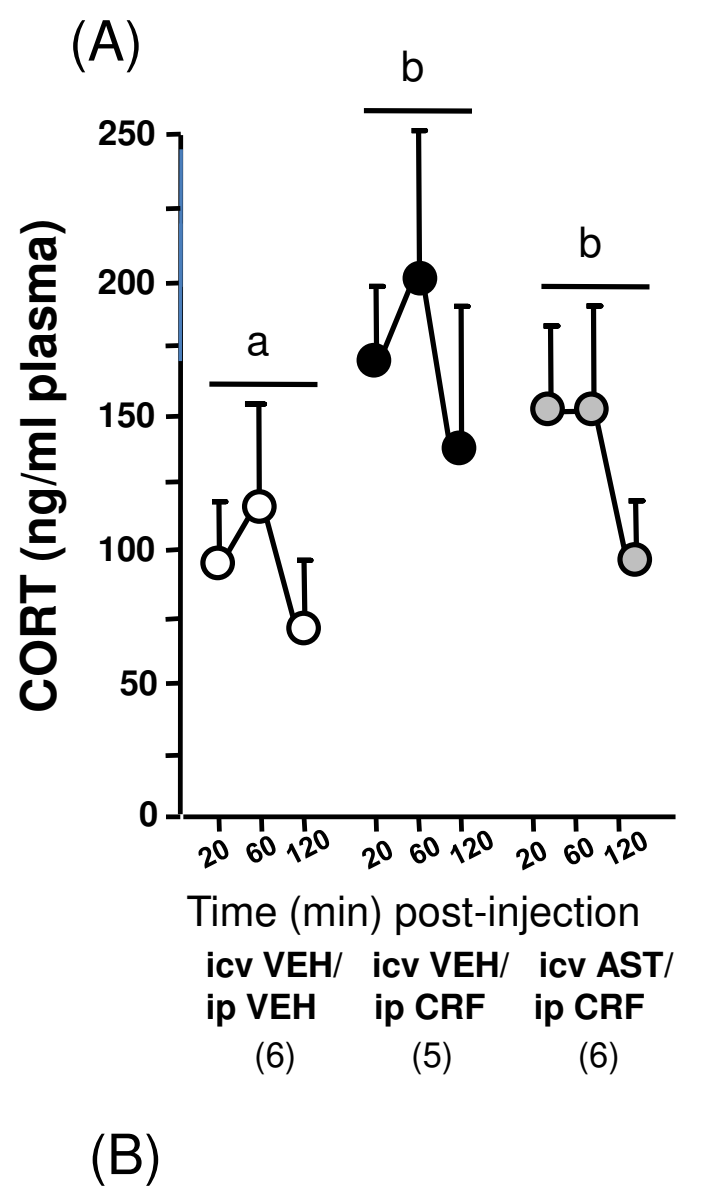


Figure 7

(A)

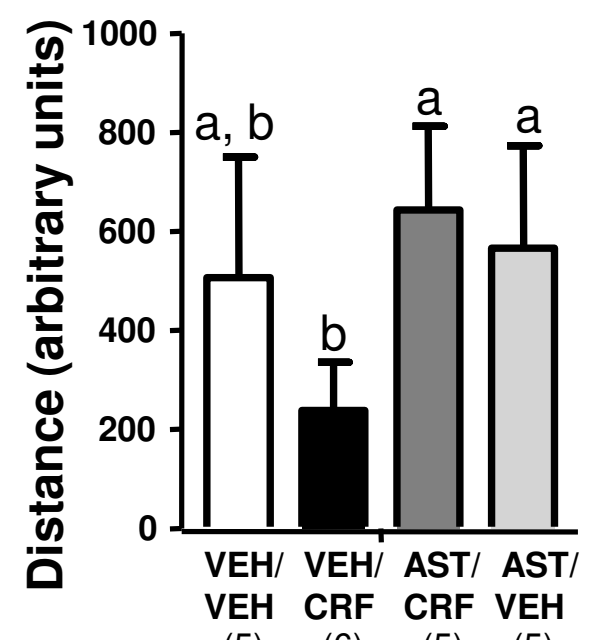

(5) (6) (5) (5)

ICV Infusion
(B)

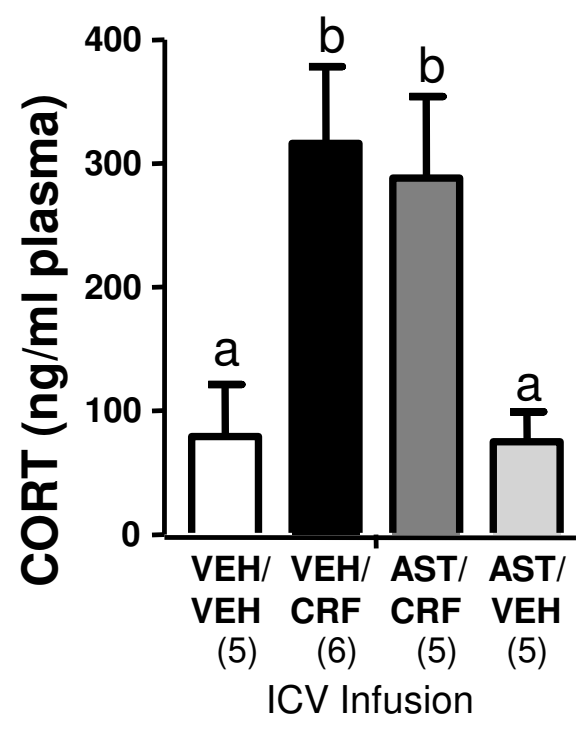

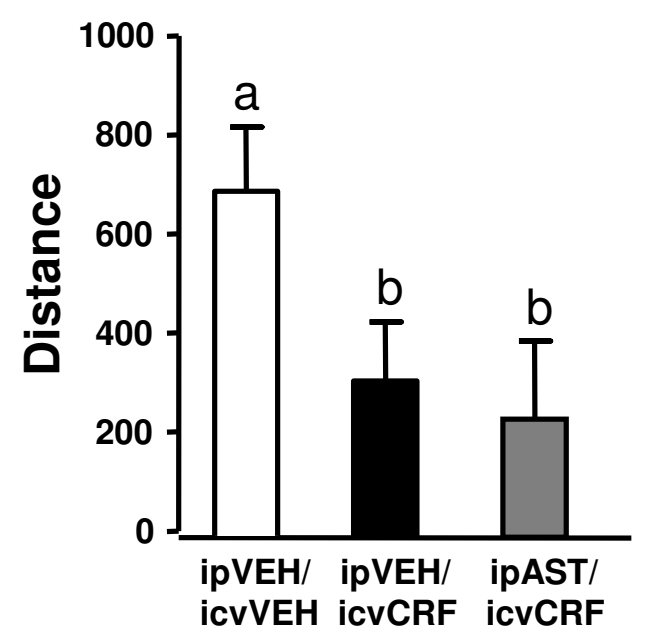

(4)

(4)

(4) 